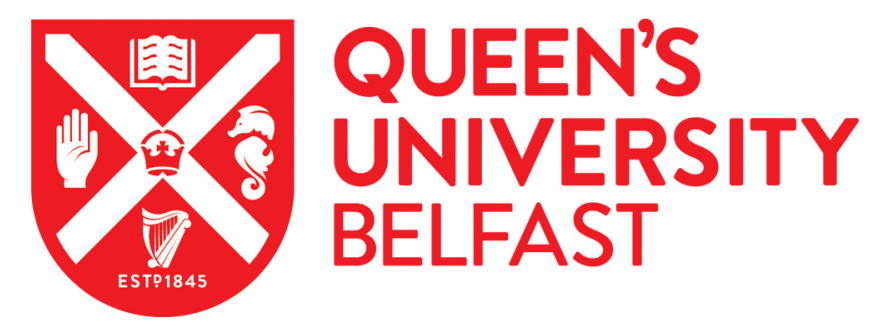

\title{
A Ricardian Analysis of the Impact of Climate Change on Italian Agriculture
}

Bozzola, M., Massetti, E., Mendelsohn, R., \& Capitanio, F. (2018). A Ricardian Analysis of the Impact of Climate Change on Italian Agriculture. European Review of Agricultural Economics, 45(1), 57-79.

https://doi.org/10.1093/erae/jbx023

Published in:

European Review of Agricultural Economics

Document Version:

Peer reviewed version

Queen's University Belfast - Research Portal:

Link to publication record in Queen's University Belfast Research Portal

Publisher rights

(C) 2017 Oxford University Press and Foundation for the European Review of Agricultural Economics.

This work is made available online in accordance with the publisher's policies. Please refer to any applicable terms of use of the publisher.

\section{General rights}

Copyright for the publications made accessible via the Queen's University Belfast Research Portal is retained by the author(s) and / or other copyright owners and it is a condition of accessing these publications that users recognise and abide by the legal requirements associated with these rights.

Take down policy

The Research Portal is Queen's institutional repository that provides access to Queen's research output. Every effort has been made to ensure that content in the Research Portal does not infringe any person's rights, or applicable UK laws. If you discover content in the Research Portal that you believe breaches copyright or violates any law, please contact openaccess@qub.ac.uk. 


\title{
A Ricardian Analysis of the Impact of Climate Change on Italian Agriculture
}

\begin{abstract}
This research investigates the potential impact of warming on Italian agriculture. Using a detailed dataset of 16,000 farms across Italy, the study examines likely warming impacts in different regions and for different sectors of Italian agriculture. The study finds that farm net revenues are very sensitive to seasonal changes in temperature and precipitation. Livestock and crop farms have different responses to climate as do rainfed farms and irrigated crop farms. The overall results suggest mild consequences from marginal changes in climate but increasingly harmful effects from more severe climate scenarios.
\end{abstract}

Keywords: Ricardian analysis, climate change, Italian agriculture, regional analysis, panel data

JEL classification: Q54, Q51, Q15 


\section{Introduction}

The literature addressing the impact of climate change on European agriculture mostly relies on crop models (Eckertsen et al., 2001; Reidsma et al., 2010; Palosuo et al., 2011; Olesen et al., 2011; Rötter et al., 2011a, 2011b, 2012; Iglesias et al., 2012; Porter et al., 2013). This literature finds that climate change may have positive effects for agriculture in Northern Europe while damages will prevail in Southern Europe. Warmer climates in Northern countries may allow new crop species and varieties, increase yields, and expand cropland (Olesen and Bindi, 2002; Ewert et al., 2005; Iglesias et al., 2012) whereas Southern Europe may experience a reduction in crop yields, higher yield variability, and a reduction in cropland.

The Ricardian method was developed to study the long-term impacts of climate change on agriculture while accounting for adaptation (Mendelsohn, Nordhaus and Shaw, 1994). This hedonic method starts from the assumption that land rents reflect the expected productivity of agriculture (Ricardo, 1817). The method estimates how much of the observed cross-sectional variation of land values (or net revenues) can be explained by climate controlling for confounding factors. The strength of the Ricardian method is its ability to measure the long run impacts of climate change taking into account the ability of each farmer to adapt.

Several studies have now estimated multi-country Ricardian models for Europe (Moore and Lobell, 2014; Van Passel, Massetti and Mendelsohn, 2016 and Vanschoenwinkel, Mendelsohn and Van Passel, 2016) and there are also several single country studies for Europe (Maddison, 2000; Lang, 2007; Lippert, Krimly and Aurbacher, 2009; Chatzopoulos and Lippert, 2015 and 2016). The Van Passel, Massetti and Mendelsohn, (2016) study finds that European farms are sensitive to warming with possible climate damage of $8 \%$ to $44 \%$ by 2100 depending on the climate scenario. Farms in Southern Europe (Spain, Portugal, Italy, Greece and South of France) are predicted to be especially vulnerable. In particular, the study predicts that about two thirds of the loss in land values in the EU is concentrated in Italy because Italy contains most of the vulnerable agricultural land in Southern Europe. It is consequently pertinent to examine Italian agriculture more closely.

This paper constructs a unique dataset of Italian farms involving a much larger number of observations for Italy alone than in Van Passel, Massetti and Mendelsohn (2016). Further, the farm level data is geo-referenced at the municipal level which is more spatially refined than NUTS3 
level used in Van Passel, Massetti and Mendelsohn (2016). This enables a closer fit between the farm data and climate, soil, geography and other socio-economic variables.

Italy is an excellent case study to investigate the impact of climate on European farms, due to the highly heterogeneous climatic, soil, socio-economic and topographical features of the Italian peninsula. By limiting the study to Italy, the paper also avoids possible problems associated with comparing farms in different countries.

We regress farmland values on climate, soils, and other control variables for our entire sample. These regressions allow us to estimate the impact of marginal and non-marginal changes in climate across Italy. We then explore regressions on sub-samples of farms depending upon whether they specialise in crops or livestock production or whether they are irrigated or rainfed. These latter results allow us to test the climate sensitivity of each type of farm. The results confirm findings from the literature that the climate sensitivity of each type of farm are different (Schlenker, Hanemann and Fisher, 2005; Kurukulasuriya and Mendelsohn, 2008; Seo and Mendelsohn, 2008b). Part of the reason the results are different for livestock versus crop farms or for irrigated versus rainfed farms is that the underlying conditions may be different. The farmers are aware of these differences but the analyst may only know some of them. This may lead to biased estimates of climate coefficients in the full sample (Timmins, 2006). But the results from sub-samples of farms must be interpreted carefully because whether a farmer grows crops or livestock or uses irrigation is a choice by farmers and farmers will likely change their choices to adapt to climate change (Timmins, 2006; Kurukulasuriya, Kala and Mendelsohn, 2011).

Contrary to Van Passel, Massetti and Mendelsohn (2016) we find that a uniform marginal increase in temperature across the year does not significantly affect land values in Italy. The effect of warming in summer is harmful, but warmer spring and autumn temperatures are beneficial. A uniform marginal increase in precipitation across the entire year is also not significant at the national level, but it is significant at the regional level. More (less) annual precipitation is significantly harmful (beneficial) in the North and significantly beneficial (harmful) in the South and in the Centre.

We examine the non-marginal climate sensitivity of current agricultural production using climate change scenarios from eight alternative General Circulation Models (GCMs) from the Climate Modelling Intercomparison Project 5 (CMIP5). The more greenhouse gases that are 
emitted (the more severe the change in climate), the larger and more likely are the harmful effects. Harmful effects also tend to increase over time for each climate scenario as temperatures increase. Although the climate scenarios used are not directly comparable with those in the study by Van Passel, Massetti and Mendelsohn (2016), the predicted impacts to Italian agriculture are smaller in this study.

The rest of the paper is structured as follows: the next section outlines the methodology and the estimation procedure used. The third section describes the data. Section four presents the main results. Section five concludes.

\section{Methodology}

This paper relies on a Ricardian analysis (Mendelsohn, Nordhaus and Shaw, 1994) of a rich dataset, comprising almost 16,000 farms across the Italian territory. The Ricardian approach is a crosssectional analysis of farm land values. Land values are regressed on a set of climate variables and control variables. The strength of the approach is its ability to measure the long run impact from climate change given likely climate adaptations by farmers. The approach is not designed to measure short term weather impacts (Kelly, Kolstad and Mitchell, 2005).

The method assumes that farmers maximize land rents given the climate and the other exogenous factors that they face. If land markets are competitive, rents will reflect the long run productivity of the land (Ricardo, 1817). Farmland prices in turn reflect the present discounted value of future land rents. The regression coefficients estimate the impact on land value of the current temperature and precipitation of each farm. Assuming each farmer has adapted to the climate they currently live in, the result reflects farm adaptation.

Farmer choices, consequently, should not be included in the Ricardian model. For example, one should not include irrigation or crop choice as an independent variable in the regression model. The Ricardian model is intended to measure outcomes allowing these choices to adjust.

One point that is important to understand is that the result of a general Ricardian model describes the net outcome across the entire agricultural system. Each farming area, having adopted a specific crop and type of farming is captured along this function. If conditions change substantially, the Ricardian function describes what would happen to that farm area if it changed into a different farm with the new conditions. The general Ricardian model does not describe what would happen if the 
farms remain the same. For example, if rainfed farms with access to water experience a prolonged drop in rainfall, the general Ricardian model would assume these farms would switch to irrigation. In contrast, if one estimated a rainfed Ricardian model with just rainfed farms, the model would assume that there would be no switching. The general Ricardian model would provide biased estimates of the outcome to rainfed farms that remain rainfed (Schlenker, Hanemann and Fisher 2005; Timmins, 2006). The rainfed Ricardian model would provide biased estimates of the outcome to farms that switch to irrigation (Mendelsohn, Nordhaus, and Shaw 1994). A structural Ricardian model could predict the probability a farm would be irrigated or rainfed and a conditional income for both irrigated cropland and rainfed cropland (Kurukulasuriya, Kala and Mendelsohn, 2011). But this requires data about water access that is not available in this data set and so is a topic for further research.

We include Ricardian estimates of crop versus livestock farms and of rainfed versus irrigated farms. We analyse these subsamples to understand how different parts of the Italian farm sector respond to climate. The analyses provide further insight into how Italian farms will be affected. The same statement applies to the macro-regional analyses which try to explain how parts of the country will be affected.

One of the weaknesses of the Ricardian model (and of all uncontrolled experiments) is the potential bias from omitted variables. Time-independent location-specific factors such as unobservable skills of farmers or unobservable soil quality can potentially bias the coefficients of observed variables they are correlated with (Deschênes and Greenstone, 2007). Panel models that use fixed effects and weather shocks to identify the relationship between climate and agricultural productivity are subject to possible omitted variable bias as many of the omitted weather variables are correlated to the regressors (Zhang, Zhang and Chen, 2017). We minimize this problem by compiling a rich dataset of geographic and socio-economic variables to include in the model. However, some variables were not available for this study such as access to surface water or groundwater.

Although the Ricardian model does measure impacts net of adaptation, it does not measure how farmers adapt (Seo and Mendelsohn, 2008a), and what specific adaptation strategies are employed by farmers (Di Falco, Veronesi and Yesuf, 2011). Separate studies that explicitly address adaptation are required to study the choice of irrigation (Kurukulasuriya, Kala and Mendelsohn, 
2011; Chatzopoulos and Lippert, 2016), crop choice (Kurukulasuriya and Mendelsohn, 2008; Seo and Mendelsohn, 2008a; Wang et al., 2010; Chatzopoulos and Lippert, 2016) and livestock choice (Seo and Mendelsohn, 2008b; 2008c).

The Ricardian method has been applied to most regions of the world (see review in Mendelsohn and Dinar, 2009). Several of the analyses, such as the studies in the United States, rely on aggregated land value data by county (Mendelsohn, Nordhaus and Shaw, 1994; Schlenker, Hanemann and Fisher, 2005 and 2006; Deschênes and Greenstone, 2007). Farm level data, such as the data in this study, are valuable because they contain important information about the type of farm allowing the Ricardian study to estimate impacts by different farm types. They also permit a more accurate measure of farm level variables.

The Ricardian model assumes that farmland value per hectare (V) of each farm $i$ is equal to the present value of future net revenues from farm activities:

$$
\mathrm{V}=\int_{t}^{\infty}\left[\sum P Q(X, G, Z)-M^{\prime} X\right] e^{-\varphi \mathrm{t}} d t
$$

where $P$ is a vector of exogenous market prices of output, $\mathrm{Q}$ is output, $\mathrm{X}$ is a vector of purchased inputs (other than land), $\mathrm{G}$ is a vector of exogenous control variables that are constant over time (e.g. climate) and $\mathrm{Z}$ is a vector of exogenous control variables that change over time (e.g. population and income per capita). We rely on climatologies (i.e., thirty year averages) of temperature and precipitations to study the long-run relationship between climate and land values. $M$ is a vector of input prices, $t$ is time and $\varphi$ is the relevant discount rate. The farmer chooses the outputs to produce and the inputs $X$ to maximize the land value at given prices, climate and other exogenous socio-economic conditions.

Assuming that farmers maximize (1) given current conditions, they will choose the output and purchased inputs that lead to the maximum farmland value per hectare. The relationship between the maximum farmland value per hectare and the exogenous variables that cannot be changed by the farmer is the Ricardian function:

$$
\mathrm{V}=\mathrm{f}(G, Z, P, M)
$$

Note that $\mathrm{G}, \mathrm{Z}, \mathrm{P}$, and $\mathrm{M}$ are all exogenous variables. In particular, we estimate the following pooled OLS model over the years 2008, 2009, 2010 and 2011:

$$
\ln V_{i, t}=\alpha+\sum_{k=1}^{4}\left(\beta_{T, k} T_{i, k}+\gamma_{T, k} T_{i, k}^{2}+\beta_{R, k} R_{i, k}+\gamma_{R, k} R_{i, k}^{2}\right)+\delta G_{i}+\zeta Z_{i, t}+u_{i, t}
$$


where the dependent variable $\ln V_{i, t}$ is the logarithm of the land value per hectare (EUR/Ha) of farm $i$ at time $t$. $\mathrm{T}$ and $\mathrm{R}$, are seasonal (seasons indexed with $\mathrm{k}=1, \ldots, 4)$ temperature and precipitation climate normals of farm $i$ that we have separated from other exogenous time invariant control variables in G. $u_{i, t}$ is a random error term which is assumed not to be correlated with climate. Input prices do not appear in (3) because agricultural markets are assumed to be competitive and prices of identical agricultural commodities to be the same across the country. Differences in local prices are explained by transportation and access to markets cost that are controlled by variables included in $\mathrm{G}$ and by regional dummies. We rely on the pooled estimate to minimize the influence of random variation that could affect the coefficients in any one year.

We rely on a log-linear Ricardian model because land values, in Italy as in other countries, are lognormally distributed (Schlenker, Hanemann and Fisher, 2006; Massetti and Mendelsohn, 2011; Fezzi and Bateman, 2015; Van Passel, Massetti and Mendelsohn, 2016).

Following the literature (Seo and Medelsohn, 2008a and 2008b; Kurukulasuriya, Kala and Mendelsohn, 2011; Massetti and Mendelsohn, 2011; Van Passel, Massetti and Mendelsohn, 2016) we look at seasonal differences in temperatures and precipitations impacting farmland productivity, and we posit a quadratic relationship between climate and land values. Schlenker, Hanemann and Fisher, (2006) estimate a Ricardian function for the Eastern United States using the sum of degree days and total precipitation between April and September instead of average temperature and total precipitations during the four seasons. Massetti, Mendelsohn and Chonabayashi (2016) show that degree days and average temperature during April-September are almost perfectly correlated and that the four-season model provides better out-of-sample forecasts than the growing season model used by Schlenker, Hanemann and Fisher (2006). A four-season model is clearly more appropriate for Italy because its generally mild climate allows perennials (e.g. olive trees) and some crops (e.g. winter wheat) to grow also during winter and early spring months. For each farm $i$ we use the climate of the local municipality. Because the municipality is comparatively small, this is one of the most spatially detailed studies in the literature (see Fezzi and Bateman (2015) for a discussion of the value of spatial detail).

We include control variables that the literature has shown to affect land value. Some of the time invariant variables in $\mathrm{G}$ are measured at the farm (latitude, longitude, elevation) level while others are measured at the municipal level (soil quality, whether a municipality is coastal or not, 
population density, average growth rate of population and tourism receptive capacity). The variables in $\mathrm{Z}$ describe farm characteristics that can change over time (farm size, percentage of rented farmland, age of farmer).

We include regional dummies to capture regional exogenous variables, such as regional agricultural policies and subsidies or other characteristics that we do not measure. ${ }^{1}$ The inclusion of regional dummies reduces the out-of-sample root means square error (RMSE) from 0.65 to $0.58 .^{2}$

We formally test the poolability over time on the balanced panel of farms. We perform the standard Chow test (Chow, 1960) and the Roy-Zellner test (Roy, 1957; Zellner, 1962), a modified version of the Chow test that accounts for the possibility of non-spherical disturbances (Baltagi, 2013). Results of both tests do not reject the null-hypothesis of equal parameters with respect to time (at $1 \%$ level). ${ }^{3}$

Earlier literature suggests that crops and livestock as well as irrigated and rainfed farms may react to climate in different ways (Mendelsohn and Dinar, 2009; Van Passel, Massetti and Mendelsohn, 2016; Chatzopoulos and Lippert, 2016). We test this hypothesis by measuring the climate sensitivity of farms that just sell crops versus farms that just sell livestock. We also estimate separate Ricardian functions for rainfed and irrigated crop farms. The small fraction in our sample of farms in Italy that engage in both crop and livestock farming were omitted from these estimates.

We calculate the percentage change in land value associated with a marginal increase in temperature and precipitation in season $k$ as follows:

$\left[\partial \widehat{V}_{i} / \partial \mathrm{T}_{\mathrm{k}}\right] / \widehat{V}_{l}=\beta_{\mathrm{T}, \mathrm{k}}+\left(2 \gamma_{\mathrm{T}, k} \mathrm{~T}_{\mathrm{i}, k}\right)$

\footnotetext{
1 Regions are NUTS2 level accordingly to the Nomenclature of Territorial Units for Statistics, defined by the European Union. The Italian territory is divided in 20 regions. Our sample includes 21 NUTS2, as the Südtirol/Trentino Alto Adige region is split into two, following the NUTS and FADN classification.

2 We draw a random sample of $70 \%$ of total farms in the study and we estimate the model presented in Equation 3 with and without regional dummies. We use the remaining $30 \%$ of the sample as a forecasting sub-sample and we calculate the RMSE of out-of-sample prediction. We repeated this procedure 1,000 times and we calculated the average out-of-sample RMSE for the model with and without regional dummies.

3 Results are available upon request. For the Chow test the null hypothesis is $H_{0}: \beta_{t}=\beta$, for $t=2008,2009,2010$, 2011. $\mathrm{F}_{\mathrm{obs}}=\left[\left(e^{\prime} e-\sum_{2008}^{2011} e_{t}^{\prime} e_{t}\right) /(T-1) K\right] /\left[\sum_{2008}^{2011} e_{t}^{\prime} e_{t} / T(n-K)\right] \sim F[(T-1) K, T(n-K)]$. The equation is estimated for the pooled sample, to obtain the unrestricted SSE $\left(e^{\prime} e\right)$ and separately for each year, to be able to calculate $\sum_{2008}^{2011} e_{t}^{\prime} e_{t}$. We obtain $\mathrm{F}_{\mathrm{obs}}=0.00003 \sim \mathrm{F}(165,27604)$ from the estimation of Equation (3) in the paper. The very small $\mathrm{F}$ statistic does not reject the null hypothesis in favor of poolable panel data with respect to time $(p<0.999)$.
} 


$$
\left[\partial \widehat{V}_{i} / \partial \mathrm{R}_{\mathrm{k}}\right] / \widehat{V}_{l}=\beta_{\mathrm{R}, \mathrm{k}}+\left(2 \gamma_{\mathrm{R}, k} R_{i, k}\right)
$$

Note that the percentage change is a function of the local climate. We use climate at the municipal level to calculate municipal level marginal effects over the whole country.

Finally, we calculate the impact on current farms of possible future climates, ceteris paribus. It is beyond the scope of this study to predict the change in prices, technology, and policies that may occur far into the future. We explore these future climate scenarios simply to provide a sense of how the climate sensitivity changes as climate changes. We compute the potential welfare impact of these climate scenarios by comparing the predicted land values at new temperatures and precipitations $\left(T_{f}, R_{f}\right)$ to the predicted land values at the historic climate $\left(T_{0}, R_{0}\right)$, for each farm. In predicting land values we account for the logarithmic transformation $\left(\widehat{V}_{i}=\right.$ $\left.\exp \left(\hat{\sigma}^{2} / 2\right) \exp \left(\widehat{\log }_{l}\right)\right)$ and we use time averages of time-varying control variables and time fixed effects. Thus, the predicted change of land value for each farm is calculated as follows:

$\widehat{\Delta V}_{l}=\sum_{i=1}^{N}\left[\widehat{V}_{i}\left(\mathrm{~T}_{\mathrm{i}, \mathrm{f}} \mathrm{R}_{\mathrm{i}, \mathrm{f}}\right)-\widehat{V}_{i}\left(\mathrm{~T}_{\mathrm{i}, 0} \mathrm{R}_{\mathrm{i}, 0}\right)\right]$

When we aggregate farm impacts over larger regions we use the sample weights provided by the FADN. ${ }^{4}$

Throughout the paper we use spatially robust standard errors (Conley, 1999) to account for spatial correlation among farms. ${ }^{5}$

\section{Data}

We construct a unique dataset of farm level agricultural data, temperature, precipitation, soil quality and socio-economic indicators for Italy. Farm level data come from the Italian Farm Accountancy Data Network (FADN/RICA). According to the FADN regulation, information is collected each year from a sample of farms, representative of Italian commercial agriculture. The total number of farms in Italy is estimated to be about 1.6 million (ISTAT, 2013). The farm data in the dataset include 15,989 farms and refer to the period 2008 to 2011. Data included in this panel is strictly

\footnotetext{
4 FADN provides a weight for each individual farm recorded in the sample. The weight for each farm reflects the number of actual farms in the FADN region that it represents. In order to calculate this individual weight, holdings in the sample and in the field of survey are stratified according to three criteria: FADN region (21 in Italy), type of farming and economic size class.

5 We followed the approach developed by Conley (1999) as implemented by Hsiang (2010). We report in all tables standard errors based on a cut-off of $100 \mathrm{~km}$.
} 
regulated and harmonized by the European Union in order to administer agricultural policies. The dataset includes the agricultural land value per hectare and other farm specific variables (e.g., irrigated area, share of rented land, mean elevation). FADN estimates the value of farmland from owner-occupied farmland using regional prices for non-rented land of similar quality sold for agricultural purposes. Farms are geo-referenced and distributed across the whole Italian peninsula.

About 55\% of 8,092 Italian municipalities are directly represented in the dataset, and these constitute about $73 \%$ of the Italian peninsula's territory. ${ }^{6}$ Some municipalities are very small in Italy and they do not provide a large enough sample of farms. For example, in Lombardy Region (the region with the lowest share of municipalities represented in our sample) $48 \%$ of the municipalities have an area of less than 10 square kilometers (ISTAT, 2013). The overall representativeness of the sample is guaranteed by stratification according to criteria of geographical representativeness, economic size and farm type.

Geographic coordinates of farms are available only from 2011 onwards and we would lose about $30 \%$ of the sample if we limited our analysis to these farms. We prefer working with a larger set of farms in a pooled panel setting to increase the precision of our estimates. For each farm we used geographic coordinates of the corresponding municipality to measure climate variables, soil quality, socio-economic and geographical variables. As municipalities are typically very small (the median surface area is $22 \mathrm{~km}^{2}$ - ISTAT, 2013) we retain a high level of spatial disaggregation. In comparison, the Italian NUTS3 regions used by Van Passel, Massetti and Mendelsohn (2016) have an average surface size equal to $2,746 \mathrm{Km}^{2}$.

Gridded temperature and precipitation data is from the Climatic Research Unit (CRU) TS3.21 dataset (Harris et al., 2014). The dataset covers the entire globe at a $0.5 \times 0.5$ degree resolution. This corresponds to grid cells approximately $56 x 56 \mathrm{~km}$ wide in Italy. Climate normals of seasonal temperature and precipitations are calculated over the 1977-2007 period. We construct municipal climate by interpolating the four closest grid cells to the centroid of each municipality using inverse distance weights. We follow the climatological definition of seasons (e.g., winter is December, January and February).

6 Municipalities are LAU2 (former NUTS5) level accordingly to the Nomenclature of Territorial Units for Statistics, defined by the European Union. 
For the non-marginal impacts of climate change, we use eight different climate models. We consider two different greenhouse gases Representative Concentration Pathways (RCPs) for each model: $\mathrm{RCP} 8.5$, which is a high range emission scenario and the $\mathrm{RCP} 4.5$, a lower range emission scenario (van Vuuren et al., 2011). We allocate the climate data generated by the climate models to each Italian municipality by interpolating the four closest grid points of the climate scenario using inverse distance weights. Estimates of the change in temperature and precipitation at the municipality level were obtained comparing predicted climate in 2071-2100 and in 2031-2060 with climate in 1971-2000, predicted by the same climate model to avoid model bias in climate change scenarios.

Soil data at the municipality level is from the Harmonized World Soil Database (FAO, IIASA, ISRIC, ISSCAS, JRC, 2012). Additional socio-economic (e.g., population density) and geographic variables (e.g., whether the farm belongs to a coastal municipality) are from the Italian National Institute for Statistics (ISTAT). Data on tourism (e.g., density of touristic establishments) is from the annual survey of the capacity of tourist accommodation establishments, conducted at municipality level. These variables are important when land value (rather than net revenue) is used as dependent variable, as they allow controlling for factors impacting land value other than agricultural use, such as land scarcity and competition with other land uses (Mela, Longhitano and Povellato, 2012). Descriptive statistics of the variables used in this study are presented in Table 1. Definitions for each variable are presented in the Appendix. 
Table 1. Descriptive statistics

\begin{tabular}{|c|c|c|c|c|c|}
\hline Variables & Mean & Median & Std. Dev. & Min & Max \\
\hline \multicolumn{6}{|l|}{ Farm variables } \\
\hline Land value ('000 Euro/ha) & 31.8 & 18.2 & 49.6 & 0.1 & 1,429 \\
\hline Agricultural used land (ha) & 33.1 & 13.1 & 63.6 & 0.1 & 3,445 \\
\hline Share rented land (ha/ha) & 0.38 & 0.15 & 0.4 & 0 & 1 \\
\hline Elevation mean ('000 m) & 2.72 & 1.98 & 2.9 & 0 & 21.6 \\
\hline Slope index & 0.81 & 0.67 & 0.5 & 0 & 4 \\
\hline Latitude (degrees North) & 43.10 & 43.61 & 2.4 & 36.4 & 47.0 \\
\hline Longitude (degrees East) & 12.05 & 12.08 & 2.7 & 6.5 & 18.9 \\
\hline Young farmer & 0.13 & 0 & 0.3 & 0 & 1 \\
\hline \multicolumn{6}{|l|}{ Climatic variables (municipality) } \\
\hline Temp. winter $\left({ }^{\circ} \mathrm{C}\right)$ & 4.6 & 4.4 & 3.7 & -7.1 & 12.1 \\
\hline Temp. spring $\left({ }^{\circ} \mathrm{C}\right)$ & 11.1 & 11.8 & 3.0 & -2.3 & 15.5 \\
\hline Temp. summer $\left({ }^{\circ} \mathrm{C}\right)$ & 20.8 & 21.5 & 3.3 & 6.3 & 24.9 \\
\hline Temp. autumn $\left({ }^{\circ} \mathrm{C}\right)$ & 13.5 & 13.6 & 3.5 & 0.7 & 20.1 \\
\hline Prec. winter (cm/month) & 7.1 & 6.7 & 1.7 & 4.2 & 15.3 \\
\hline Prec. spring (cm/month) & 7.2 & 6.5 & 2.7 & 2.7 & 17.1 \\
\hline Prec. summer (cm/month) & 6.1 & 5.1 & 4.2 & 0.4 & 22.0 \\
\hline Prec. autumn (cm/month) & 9.5 & 9.1 & 2.3 & 6.0 & 20.1 \\
\hline \multicolumn{6}{|l|}{ Socio-economic and geographic variables (municipality) } \\
\hline Population density 2011 ('000) & 2.5 & 1.3 & 4.3 & 0.01 & 110.9 \\
\hline Population growth $2001-2011$ & 0.04 & 0.04 & 0.1 & -0.3 & 0.9 \\
\hline Density of conventional dwellings ('000 units $/ \mathrm{km}^{2}$ ) & 1.2 & 0.6 & 1.9 & 0.01 & 38.7 \\
\hline Density of touristic establishments (units $/ \mathrm{km}^{2}$ ) & 0.15 & 0.04 & 0.7 & 0 & 39.4 \\
\hline \multicolumn{6}{|l|}{ Soil characteristics (municipality) } \\
\hline Gravel (\%vol) & 9.7 & 9.3 & 2.9 & 2.8 & 23.5 \\
\hline Sand (\%wt) & 45.0 & 42.4 & 8.0 & 14.2 & 82.3 \\
\hline Nutrient - Cec_soil (cmol/kg) & 15.7 & 16.0 & 2.9 & 4.3 & 53.5 \\
\hline $\mathrm{pH}(-\log (\mathrm{H}+))$ & 6.6 & 6.7 & 0.5 & 2.2 & 7.5 \\
\hline
\end{tabular}

Note: The medians provide a better overview of the farm sample's characteristics because the distribution of variables is right-skewed. 


\section{Result}

\subsection{Temperature and Precipitation Marginal Effects}

The Ricardian regression of Equation 3 is presented in Table A3 in the Appendix. Most of the seasonal climate coefficients are highly significant. The climate coefficients of the squared terms are significant implying that the climate effects tend to be nonlinear. Because the raw coefficients are difficult to interpret, we present in Table 2 the percentage impact of marginal climate changes, calculated using Equation 4. The effects of temperature differ by season. A $1{ }^{\circ} \mathrm{C}$ increase in summer temperature reduces land values by $62 \%$ for Italy as a whole. But a $1{ }^{\circ} \mathrm{C}$ warming in spring increases land values by $37 \%$. The effect of a marginal change in winter and autumn temperature is insignificant. The consequence of a uniform increase of $1{ }^{\circ} \mathrm{C}$ across all four seasons is the sum

of the seasonal effects. It is not significant because the seasonal effects offset each other. The result suggests that a uniform increase of $1{ }^{\circ} \mathrm{C}$ across all four seasons will have no significant effect on Italian farm values. Increases in just summer temperatures, however, would be very harmful. In contrast, Van Passel, Massetti and Mendelsohn (2016) estimate that there would be only a 5\% loss.

For Italy as a whole, a marginal increase (decrease) in precipitation has strong negative (positive) effects in autumn and winter but a positive (negative) effect in spring and summer. However, the net annual effect of a uniform increase in precipitation is insignificant at the national level. The effects for precipitation do differ across the regions of Italy. The annual effect of more (less) precipitation is harmful (beneficial) in the North but beneficial (harmful) in the Centre and South. This is likely due to the fact that the North has much higher levels of precipitation than the rest of the country. 
Table 2. Percentage impact of marginal change in climate by macro-region

\begin{tabular}{|c|c|c|c|c|c|c|c|c|c|c|}
\hline & \multicolumn{5}{|c|}{ Temperature $\left(+1^{\circ} \mathrm{C}\right)$} & \multicolumn{5}{|c|}{ Precipitation $(+1 \mathrm{~cm})$} \\
\hline & Annual & Winter & Spring & Summer & Autumn & Annual & Winter & Spring & Summer & Autumn \\
\hline \multirow[t]{2}{*}{ All of Italy } & $\begin{array}{c}-0.011 \\
(0.025)\end{array}$ & $\begin{array}{c}-0.074 \\
(0.126)\end{array}$ & $\begin{array}{c}0.366^{* * * *} \\
(0.121)\end{array}$ & $\begin{array}{c}-0.618 * * * \\
(0.153)\end{array}$ & $\begin{array}{c}0.315 \\
(0.207)\end{array}$ & $\begin{array}{c}0.012 \\
(0.037)\end{array}$ & $\begin{array}{c}-0.138^{* * *} \\
(0.050)\end{array}$ & $\begin{array}{l}0.078 * \\
(0.045)\end{array}$ & $\begin{array}{c}0.152 * * * \\
(0.047)\end{array}$ & $\begin{array}{c}-0.080 * * \\
(0.040)\end{array}$ \\
\hline & {$\left[\begin{array}{ll}-.060 & .039\end{array}\right]$} & {$\left[\begin{array}{ll}-.320 & .173\end{array}\right]$} & {$\left[\begin{array}{ll}.129 & .603\end{array}\right]$} & {$\left[\begin{array}{ll}-.918 & -.319] \\
\end{array}\right.$} & {$\left[\begin{array}{ll}-.091 & .721\end{array}\right]$} & {$\left[\begin{array}{ll}-.061 & .086\end{array}\right]$} & {$\left[\begin{array}{ll}-.236 & -.040]\end{array}\right.$} & {$\left[\begin{array}{ll}-.010 & .167\end{array}\right]$} & {$\left[\begin{array}{ll}.060 & .244\end{array}\right]$} & {$\left[\begin{array}{ll}-.159 & -.001\end{array}\right]$} \\
\hline North & $\begin{array}{c}-0.030 \\
(0.029)\end{array}$ & $\begin{array}{c}-0.222 \\
(0.183)\end{array}$ & $\begin{array}{c}0.451 * * * \\
(0.124)\end{array}$ & $\begin{array}{c}-0.789 * * * \\
(0.156)\end{array}$ & $\begin{array}{l}0.531 * \\
(0.291)\end{array}$ & $\begin{array}{c}-0.119 * * * \\
(0.041)\end{array}$ & $\begin{array}{c}-0.129 * * * \\
(0.049)\end{array}$ & $\begin{array}{c}-0.034 \\
(0.050)\end{array}$ & $\begin{array}{c}0.103 * * \\
(0.045)\end{array}$ & $\begin{array}{c}-0.060 \\
(0.040)\end{array}$ \\
\hline \multirow[t]{2}{*}{ Centre } & $\begin{array}{c}0.012 \\
(0.027)\end{array}$ & $\begin{array}{c}-0.024 \\
(0.115)\end{array}$ & $\begin{array}{c}0.342 * * * \\
(0.122)\end{array}$ & $\begin{array}{c}-0.553 * * * \\
(0.154)\end{array}$ & $\begin{array}{c}0.247 \\
(0.188)\end{array}$ & $\begin{array}{c}0.080 * * \\
(0.039)\end{array}$ & $\begin{array}{c}-0.160 * * * \\
(0.053)\end{array}$ & $\begin{array}{c}0.144 * * * \\
(0.054)\end{array}$ & $\begin{array}{c}0.178 * * * \\
(0.053)\end{array}$ & $\begin{array}{c}-0.082 * * \\
(0.040)\end{array}$ \\
\hline & {$[-.040$.064] } & {$[-.250 \quad .202]$} & {$\left[\begin{array}{ll}.102 & .582\end{array}\right]$} & {$\left[\begin{array}{ll}-.854 & -.251\end{array}\right]$} & {$[-.123 \quad .616]$} & {$\left[\begin{array}{ll}.003 & .157]\end{array}\right]$} & {$\left[\begin{array}{ll}-.265 & -.055\end{array}\right]$} & {$\left[\begin{array}{ll}.039 & .249\end{array}\right]$} & {$\left[\begin{array}{ll}.074 & .283\end{array}\right]$} & {$\left[\begin{array}{ll}-.161 & -.003\end{array}\right]$} \\
\hline \multirow[t]{2}{*}{ South } & $\begin{array}{c}0.003 \\
(0.033)\end{array}$ & $\begin{array}{c}0.109 \\
(0.120)\end{array}$ & $\begin{array}{l}0.259 * \\
(0.136)\end{array}$ & $\begin{array}{c}-0.413 * * * \\
(0.160)\end{array}$ & $\begin{array}{c}0.048 \\
(0.173)\end{array}$ & $\begin{array}{c}0.160 * * * \\
(0.045)\end{array}$ & $\begin{array}{c}-0.139 * * * \\
(0.050)\end{array}$ & $\begin{array}{c}0.199 * * * \\
(0.065)\end{array}$ & $\begin{array}{c}0.207 * * * \\
(0.063)\end{array}$ & $\begin{array}{c}-0.107 * * \\
(0.043)\end{array}$ \\
\hline & {$\left[\begin{array}{ll}-.062 & .069\end{array}\right]$} & {$[-.125 \quad .344]$} & {$[-.008$. 526$]$} & {$[-.726-.100]$} & {$[-.291 \quad .387]$} & {$\left[\begin{array}{ll}.072 & .249\end{array}\right]$} & {$\left[\begin{array}{ll}-.237 & -.041]\end{array}\right.$} & {$\left[\begin{array}{ll}.072 & .326\end{array}\right]$} & {$\left[\begin{array}{ll}.083 & .331\end{array}\right]$} & {$\left[\begin{array}{ll}-.191 & -.023\end{array}\right]$} \\
\hline
\end{tabular}

Notes: Coefficients from Table A3. The dependent variable is the logarithm of farmland value (EUR/ha). Spatially corrected standard errors in parenthesis and $95 \%$ confidence intervals in brackets. 

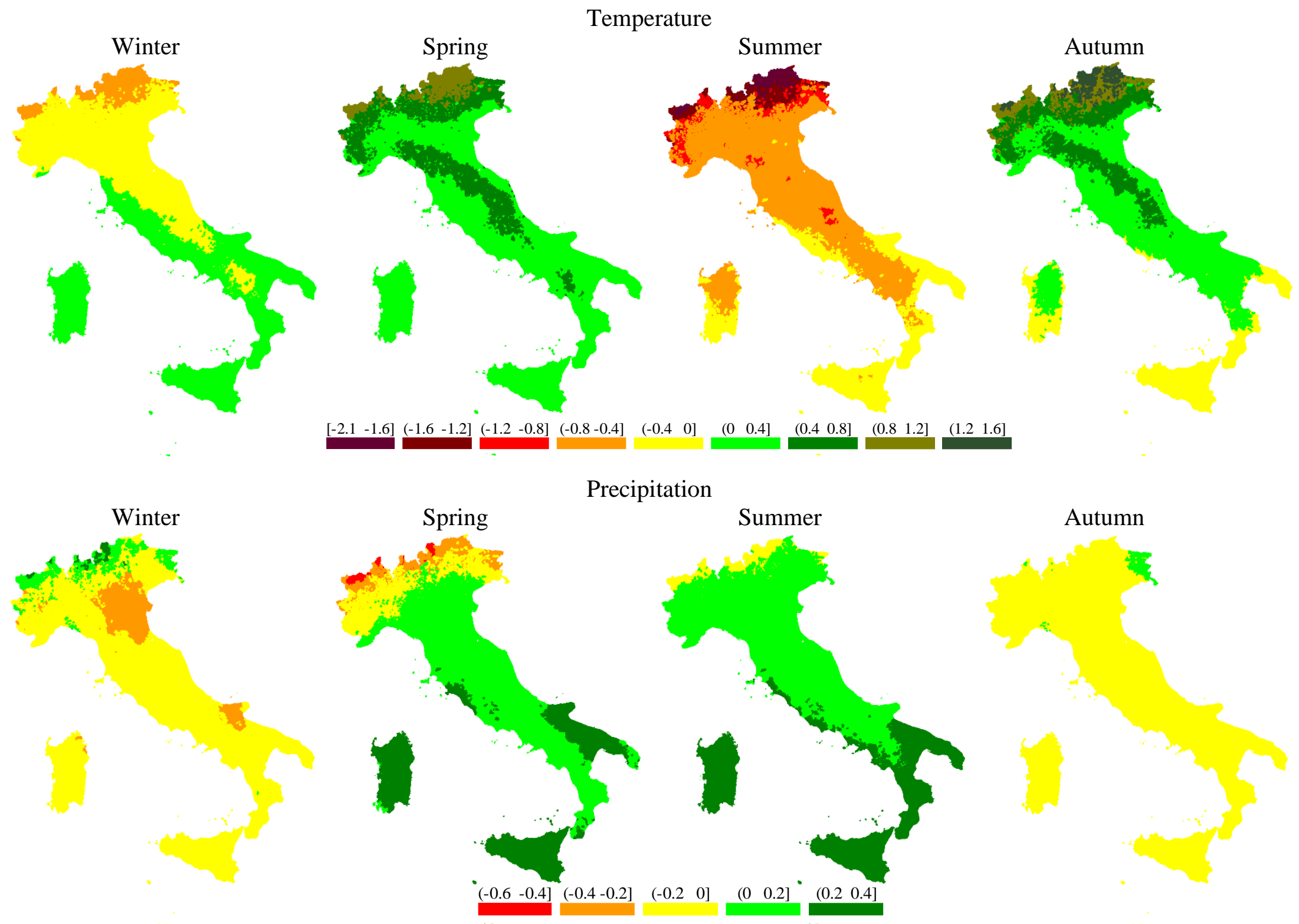

Fig. 1. Temperature $\left(+1{ }^{\circ} \mathrm{C}\right)$ and precipitation $(+1 \mathrm{~cm} /$ month) marginal impact on land values ( $000 \mathrm{EUR} / \mathrm{ha})$. 
Figure 1 presents maps of the seasonal changes in land values per $1^{\circ} \mathrm{C}$ of warming and per $1 \mathrm{~cm} /$ month of additional precipitation. We calculate the marginal impacts for each municipality, using the average marginal impact at province level for the municipalities not represented in the sample.

The range of marginal impacts varies greatly across the Italian Peninsula and across seasons. Today's coldest parts of Italy will be those most hurt by winter warming. Although all regions are affected in summer, there is a north-south pattern suggesting more harm in the North and the Apennine Mountains. Nevertheless, the north and the Apennine Mountains benefit more from warmer autumns and springs. Higher spring and autumn temperatures are beneficial because they extend the growing season for many crops.

The spring effect of more precipitation is harmful in the Alps but beneficial in the rest of the peninsula. An increase in summer precipitation is in general beneficial across the peninsula. Southern regions and the islands of Sicily and Sardinia benefit the most from a marginal increase in spring and summer precipitation, presumably because they are currently very dry.

\subsection{Ricardian regression: sub-sample analysis}

Previous research has shown that different farm types react differently to climate (e.g. Van Passel, Massetti and Mendelsohn, 2016; Chatzopoulos and Lippert, 2015; De Salvo, Raffaelli and Moser, 2013; Kurukulasuriya and Mendelsohn, 2008). We follow this literature and test whether farms specialized in crops have a different climate sensitivity than farms specialized in livestock in Italy. Cropland farms outnumber livestock farms almost three to one. We also test whether irrigated crop farms differ from rainfed crop farms in climate sensitivity. We continue to rely on the regional fixed effects model (Equation 3).

Farm type is an endogenous choice by farmers. This exercise does not explain the choice of farm type, merely the climate sensitivity of farms that have chosen to be different types. Note that these different subsamples have very similar climate characteristics (See Table A-2 in the Appendix). Irrigated crop farms tend to have a slightly cooler climate and more rainfall than rainfed crop farms, but the differences are small. Crop farms have slightly warmer and dryer climate.

The detailed results of the regressions for each subsample are shown in Table A4 and Table A5 in the Appendix. Table 3 summarises the effects of marginal changes in seasonal temperature and 
precipitation for each subsample. Separate non-marginal impacts for irrigated and rainfed farms are presented in Section 4.3.

Table 3. Percentage impact of marginal change in climate by type of farm

\begin{tabular}{|c|c|c|c|c|c|c|c|}
\hline & \multicolumn{3}{|c|}{ Temperature $\left(+1^{\circ} \mathrm{C}\right)$} & \multicolumn{3}{|c|}{ recipitation $(+1 \mathrm{~cm})$} \\
\hline & & Coef. & Std. Err. & $95 \%$ Con & Coef. & Std. Err. & $95 \% \mathrm{Co}$ \\
\hline \multirow{3}{*}{ نั } & A & -0.040 & {$[0$} & {$\left[\begin{array}{lll}-0.093 & 0\end{array}\right.$} & $0.127 *$ & [0.046] & {$[0,000$} \\
\hline & Winter & $-0.340 * * *$ & {$[0.1]-$} & {$\left[\begin{array}{lll}-0.570 & -0.110\end{array}\right]$} & -0.085 & [0.057] & {$[-0.197$} \\
\hline & Spring & $0.234 * *$ & [0.113] & {$[0.013 \quad 0.456]$} & $0.139 * * *$ & {$[0.047]$} & {$\left[\begin{array}{lll}0.047 & 0.231\end{array}\right]$} \\
\hline \multirow[t]{2}{*}{ - } & Sum & $-0.837^{* * *}$ & {$[0$.} & {$\left[\begin{array}{ll}-1.163 & -0.511\end{array}\right]$} & & & {$[0.087$} \\
\hline & Aut & 0.90 & {$[0.1$} & {$[0.5231 .193]$} & & {$[0$.} & {$[-0.202-]$} \\
\hline \multirow{5}{*}{ 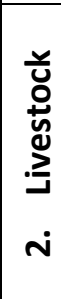 } & Anl & -0.005 & {$[0 .(1$} & {$\left[\begin{array}{ll}-0.049 & 0.0\end{array}\right.$} & -0.050 & {$[0$.} & {$\left[\begin{array}{ll}-0.137 & 0.0\end{array}\right.$} \\
\hline & Winter & -0.018 & {$[0.1$} & {$[-0.266 \quad 0.229]$} & $0.113 * * *$ & 12] & {$\left[\begin{array}{ll}0.030 & 0.195\end{array}\right]$} \\
\hline & Spring & $0.453 * * *$ & {$[0.1$} & {$\left[\begin{array}{ll}0.201 & 0.705\end{array}\right]$} & $-0.159^{* *}$ & [0.064] & {$\left[\begin{array}{ll}-0.284 & -0.033\end{array}\right]$} \\
\hline & Summer & $-0.166^{* *}$ & {$[0.0$} & {$[-0.307-0.0$} & $0.111^{* * *}$ & [0.036] & {$\left[\begin{array}{ll}0.041 & 0.1\end{array}\right.$} \\
\hline & Autumn & -0.274 & {$[0.245]$} & {$\left[\begin{array}{lll}-0.754 & 0.2(\end{array}\right.$} & $-0.115^{* *}$ & [0.047] & [-0.208 -0.022$]$ \\
\hline \multirow{2}{*}{\multicolumn{2}{|c|}{$\begin{array}{l}\text { Wald Chi- } \\
\text { square test }\end{array}$}} & \multicolumn{3}{|c|}{$\begin{array}{l}\text { H0: temperature coefficients are the same } \\
\qquad \operatorname{chi} 2(8)=34.03\end{array}$} & \multirow{2}{*}{\multicolumn{3}{|c|}{$\begin{array}{c}\text { H0: precipitation coefficients are the same } \\
\text { chi } 2(8)=21.14 \\
\text { Prob }>\text { chi } 2=0.0068\end{array}$}} \\
\hline & & & $\mathrm{b} b>\operatorname{chi} 2=$ & 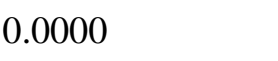 & & & \\
\hline \multirow{5}{*}{ 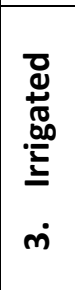 } & & $-0.086 * *$ & {$[0.0$} & {$[-0.154-0.017]$} & 0.082 & {$[0.0$} & {$\left[\begin{array}{lll}-0.020 & 0.185\end{array}\right]$} \\
\hline & Winter & -0.59 & {$[0.1$} & {$\left[\begin{array}{ll}-0.923 & -0.2\end{array}\right.$} & -0.1 & & {$\left[\begin{array}{ll}-0.261 & 0.001\end{array}\right]$} \\
\hline & Spring & 0.129 & {$[0.1$} & {$[-0.124 \quad 0.383$} & $0.190 * * *$ & [0.059] & {$\left[\begin{array}{ll}0.073 & 0.306\end{array}\right]$} \\
\hline & Summer & $-0.854 * * *$ & {$[0.191]$} & {$\left[\begin{array}{ll}-1.229 & -0.479\end{array}\right]$} & *** & {$[0$.} & {$\left[\begin{array}{ll}0.020 & 0.237\end{array}\right]$} \\
\hline & Autumn & $1.230^{* * *}$ & {$[0.3$} & {$\left[\begin{array}{ll}0.569 & 1.891]\end{array}\right.$} & & {$[0.1$} & {$[-0.2170 .006]$} \\
\hline \multirow{5}{*}{ 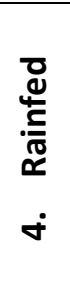 } & Annt & 0.0 & & {$\left[\begin{array}{ll}0.016 & 0.0\end{array}\right.$} & -0.046 & [0.044] & {$\left[\begin{array}{lll}-0.132 & 0.0\end{array}\right.$} \\
\hline & Winter & $0.279 * * *$ & [0.086] & {$\left[\begin{array}{ll}0.111 & 0.448\end{array}\right]$} & $-0.089 * *$ & [0.038] & {$\left[\begin{array}{ll}-0.164 & -0.014\end{array}\right]$} \\
\hline & Spring & 0.2 & {$[0.1$} & {$\left[\begin{array}{lll}-0.017 & 0.4\end{array}\right.$} & $0.113 * * *$ & {$[0.033]$} & {$\left[\begin{array}{ll}0.047 & 0.178\end{array}\right]$} \\
\hline & Summer & -0.018 & [0.072] & {$\left[\begin{array}{lll}-0.159 & 0.1\end{array}\right.$} & 0.037 & [0.044] & {$\left[\begin{array}{ll}-0.048 & 0.123\end{array}\right]$} \\
\hline & Autumn & $-0.413^{* *}$ & [0.183] & {$[-0.772-0.053]$} & $-0.107^{* * * *}$ & [0.024] & {$[-0.155-0.059]$} \\
\hline \multirow{2}{*}{\multicolumn{2}{|c|}{$\begin{array}{l}\text { Wald Chi- } \\
\text { square test }\end{array}$}} & \multicolumn{3}{|c|}{$\begin{array}{l}\text { H0: temperature coefficients are the same } \\
\qquad \operatorname{chi} 2(8)=63.98\end{array}$} & \multirow{2}{*}{\multicolumn{3}{|c|}{$\begin{array}{c}\text { H0: precipitation coefficients are the same } \\
\text { chi } 2(8)=59.64 \\
\text { Prob }>\text { chi } 2=0.0000\end{array}$}} \\
\hline & & & $>c \mathrm{ch}$ & 0000 & & & \\
\hline
\end{tabular}

Notes: The marginal impacts are evaluated at the mean temperature and precipitation of each sample (see Table A2 in the Appendices). The dependent variable is the logarithm of farmland value (EUR/ha). Spatially corrected standard errors and $95 \%$ confidence intervals in brackets. 
The results reveal that each farm type has a different climate sensitivity. The Wald chi-square tests of the hypothesis that the temperature and precipitation coefficients are the same for crop and livestock farms are rejected at the $1 \%$ significance level. The hypothesis that temperature and precipitation coefficients are the same for crop irrigated and crop rainfed farms is also rejected at the $1 \%$ significance level.

Temperature effects have the same sign for crop and livestock farms. Crop farms however have larger and more significant seasonal temperature effects than livestock farms for all seasons but spring. In particular, warmer autumns are significantly more beneficial for crop farms because many crops need warm autumns to fully ripen. The effects of a marginal change in precipitation on crop and livestock farms tend not to be significantly different.

Irrigated and rainfed crop farms have different climate sensitivities as expected. Higher annual temperatures are harmful for irrigated land but beneficial for rainfed land. The seasonal patterns are quite different. Warmer winters are harmful to irrigated farms whereas they are beneficial to rainfed farms. In contrast, warmer autumns benefit irrigated farms but harm rainfed farms. Higher spring temperatures benefits rainfed farms but have no effect on irrigated farms. A marginal change in annual precipitation has no effect on the value of either irrigated or rainfed farms. The seasonal precipitation coefficients of rainfed and irrigated farms are not identical but they are not significantly different either.

To explain what causes the differences in climate sensitivity across farm types one must use different models that allow for farm type selection. This is beyond the scope of this paper and we leave these interesting questions to further research.

\subsection{Non Marginal Impacts}

In this section we present estimates of impacts of possible future climate change scenarios. We use the spatially detailed climate scenarios of eight General Circulation Models: (i) NorESM1-M, (ii) MIROC5, (iii) MPI-ESM-MR, (iv) GFDL-CM3, (v) CCSM4, (vi) INMCM4, (vii) CMCC-CM, (viii) ACCESS1-0. Further information on the models is available in the Appendix. We compare medium (2031-2060) versus long (2071-2100) run outcomes and low (RCP 4.5) versus high (RCP 8.5) emission pathways. We study the possible impact of climate change on current Italian farmland values ceteris paribus, i.e. assuming that all other factors that affect land values remain unchanged. 
The analysis is not a forecast of future outcomes but rather an examination of the non-marginal climate sensitivity of current agricultural production.

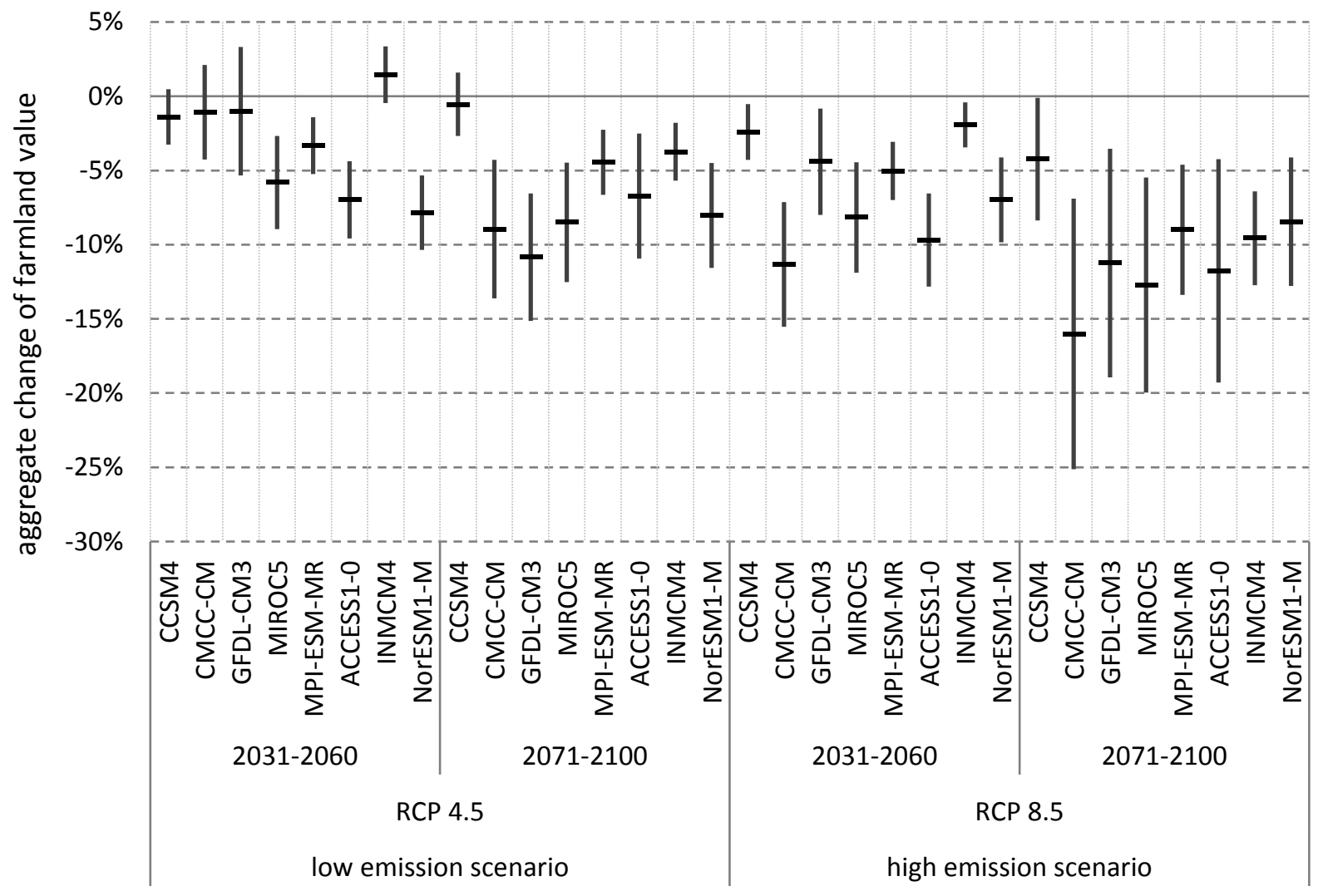

Note: Expected value and $95 \%$ bootstrap confidence intervals.

Fig. 2. Percentage change in Italian Farmland Values across Climate Scenarios.

Figure 2 displays the aggregate percentage change of farmland values in alternative climate scenarios with $95 \%$ bootstrap confidence intervals. The point estimates of climate impacts vary depending on the climate models, cumulative future emissions, and the time horizon. The aggregate non-marginal climate impacts of current agricultural production are predicted to be either neutral or harmful but rarely positive. The impacts of the medium term climate scenarios for the RCP 4.5 emission pathway are evenly split between being neutral and harmful outcomes depending on the climate model. With the high emissions of RCP 8.5, the impact of the medium term scenarios is entirely harmful, ranging from a $2 \%$ to a $12 \%$ loss of aggregate farmland value. With the longer term climate scenarios associated with the end of this century, only one out of 16 scenarios is estimated to have a neutral effect and the rest are harmful. With the RCP 4.5 emission pathway, impacts range from a loss of $1 \%$ to $11 \%$ of aggregate farmland values. With the high emission 
scenario (RCP 8.5), impacts range from a loss of $4 \%$ to a loss of $16 \%$ of aggregate land values. The results suggest that the warmer far future scenarios lead to more severe impacts. The different climate scenarios have dramatically different impacts across the regions of Italy.

Figures 3 presents the non marginal impacts in 2031-2060 for the low (RCP 4.5) emission pathway and Figure 4 presents the 2031-2060 results for the high (RCP 8.5) emission pathway. There is a lot of variation between the eight different climate model predictions in each figure. For most of the model predictions, climate change causes significant negative effects in the Southern regions. Many of the climate models also suggest that the northern Alpine region will be hurt, although quite a few models predict the opposite. Regions in the Centre of Italy are not as severely hit, and in many cases impacts there are statistically insignificant.

At both the national and regional level, climate change impacts are more harmful under high emission pathways than low emission pathways, in some cases switching from neutral or positive annual impacts to negative ones as emissions accumulate. However, the relationship between emissions and impacts at the regional level is complex. There is a great deal of uncertainty about local climate change projections at the regional level for the same level of GHG emissions. This translates into very different regional impacts, as shown by Figures 3 and 4. 

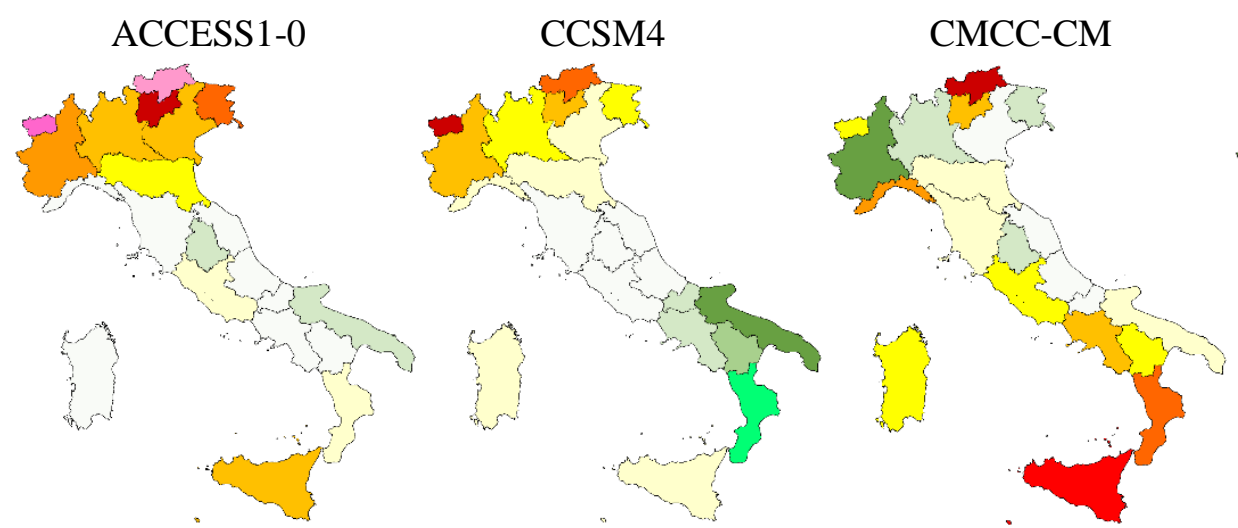

GFDL-CM3
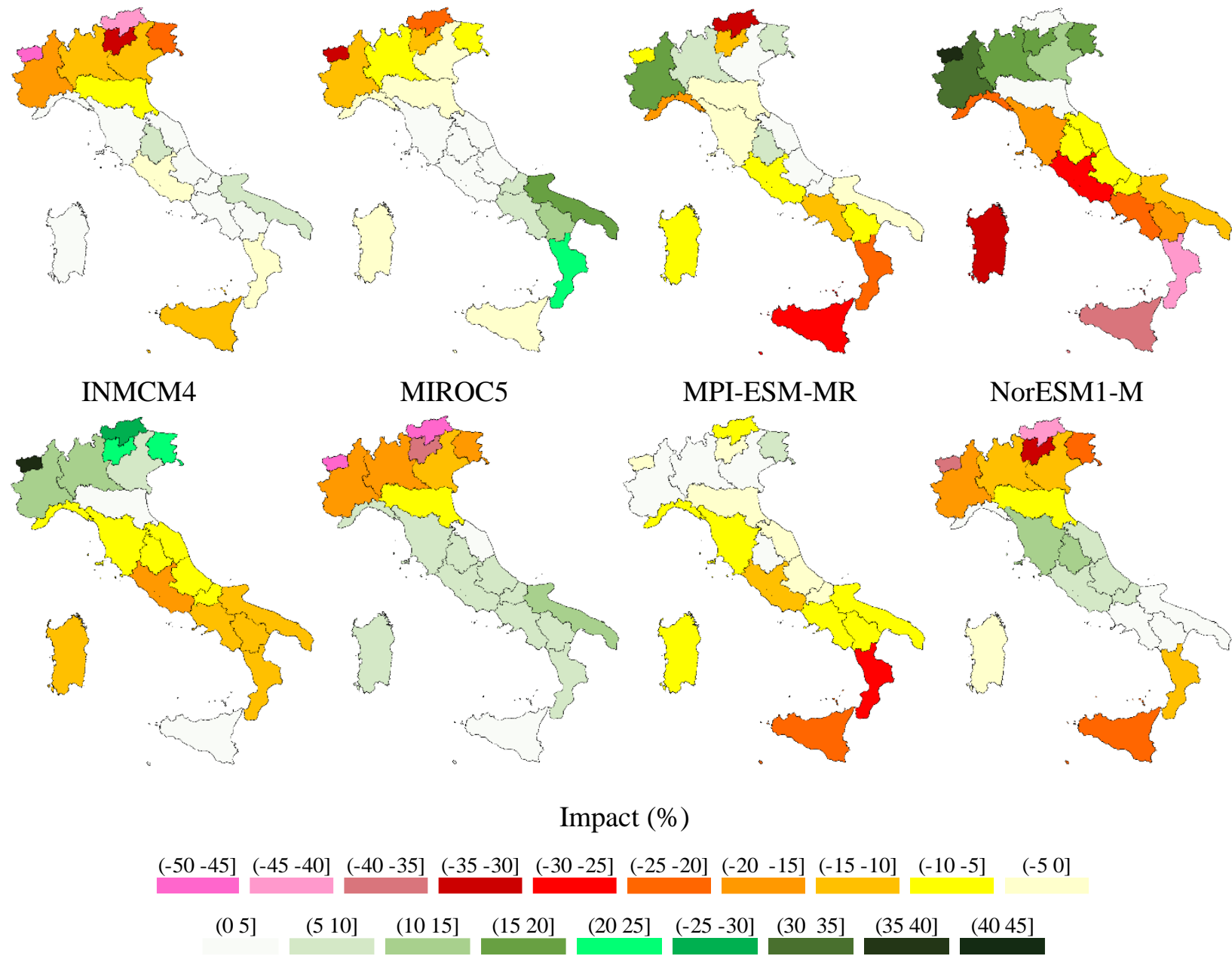

Fig. 3. Percentage change in farmland value by NUTS2 regions by climate model during 2031-2060 with RCP 4.5 emissions (low emission scenarios). 

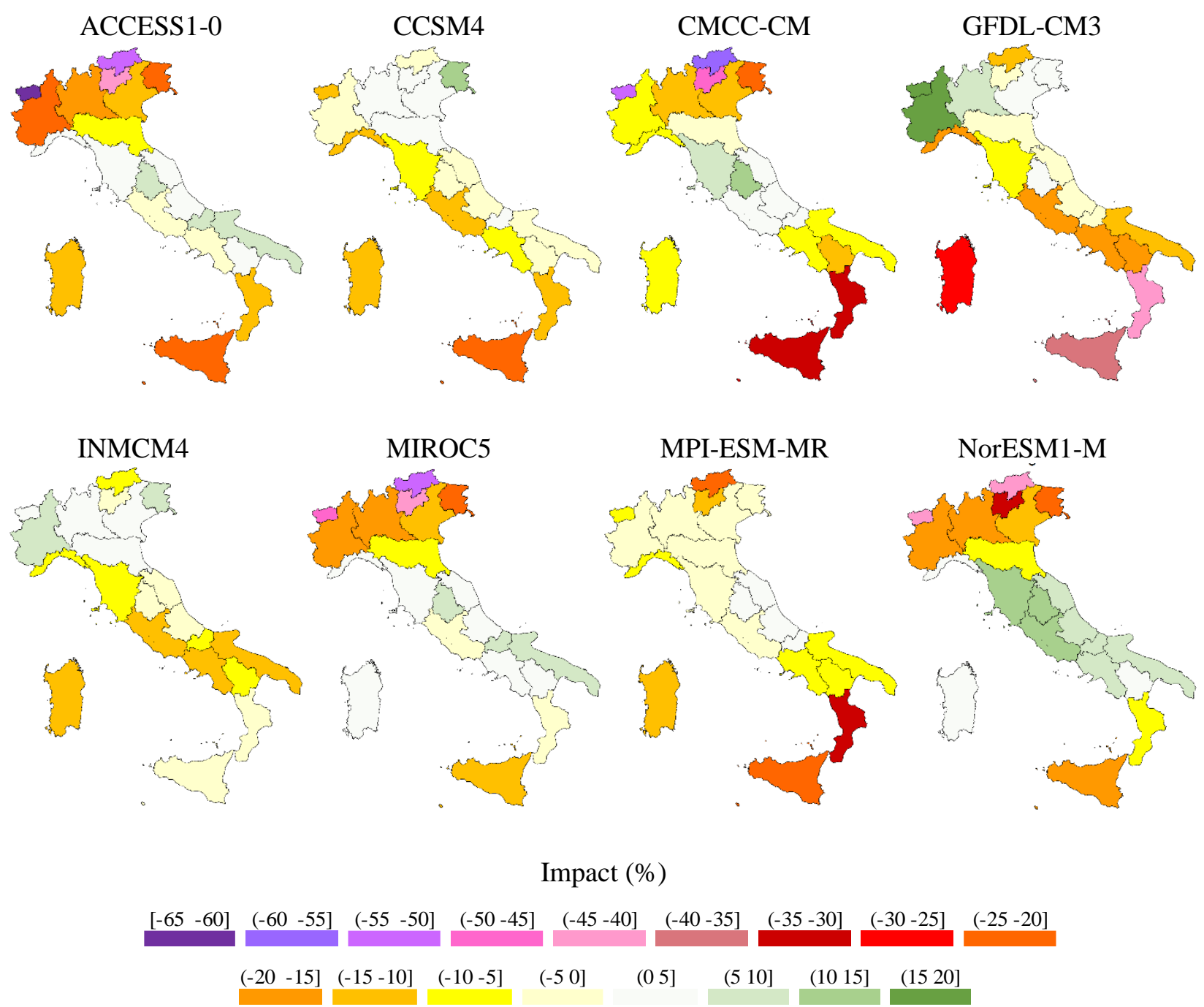

Fig. 4. Percentage change in farmland value by NUTS2 regions by climate model during 2031-2060 with RCP 8.5 emissions (high emission scenarios).

The regions that will most likely suffer from negative impacts are Alto Adige, Sicily, Trentino, Aosta Valley, Sardinia and Calabria. The regions for which most models and scenarios predict statistically significant positive impacts are Umbria, Molise, Abruzzo (in the Centre) and Puglia (in the South).

In a few cases, negative impacts are slightly more detrimental under the low emission scenario than in the case of high emission pathways, for example in some region in the South for the NorESM1-M scenario. The climate model in this case predicts a larger change in climate in this province in the low emission scenario. But in general, the climate models predict larger climate changes as emission rates increase. The high emission scenario also suggests larger confidence intervals on the climate impacts, at the national level (Figure 2) and especially at provincial levels 
(Figures A1 to A21). An effect of shifting from a high to a low emission scenario is the reduction of uncertainty in how climate will affect different parts of Italian agriculture.

Finally, we compare the effect of climate change on land values for irrigated and rainfed crop farms separately. We use the coefficients presented in Table 3 and the same set of climate scenarios used for the full sample of farms. Expected values and confidence intervals for both sub-samples of farms are presented in Figure 5. The estimates assume adaptation within each sub-sample, but irrigation choices cannot change. Impacts are mostly non-significant for rainfed crop farms, also under the most severe climate change scenario at the end of the century. Irrigated farms impacts are instead proportionally larger than for the whole sample. One possible explanation for these results is that irrigated farms specialize in crops that are more sensitive to climate than non-irrigated farms, however, our model cannot explain the differences across the two farm types. The aggregate effect of climate change (rainfed plus irrigated crop farms) is larger when using two separate Ricardian regressions under most climate change scenarios, which is a direct consequence of not allowing farmers to make different irrigation choices. 

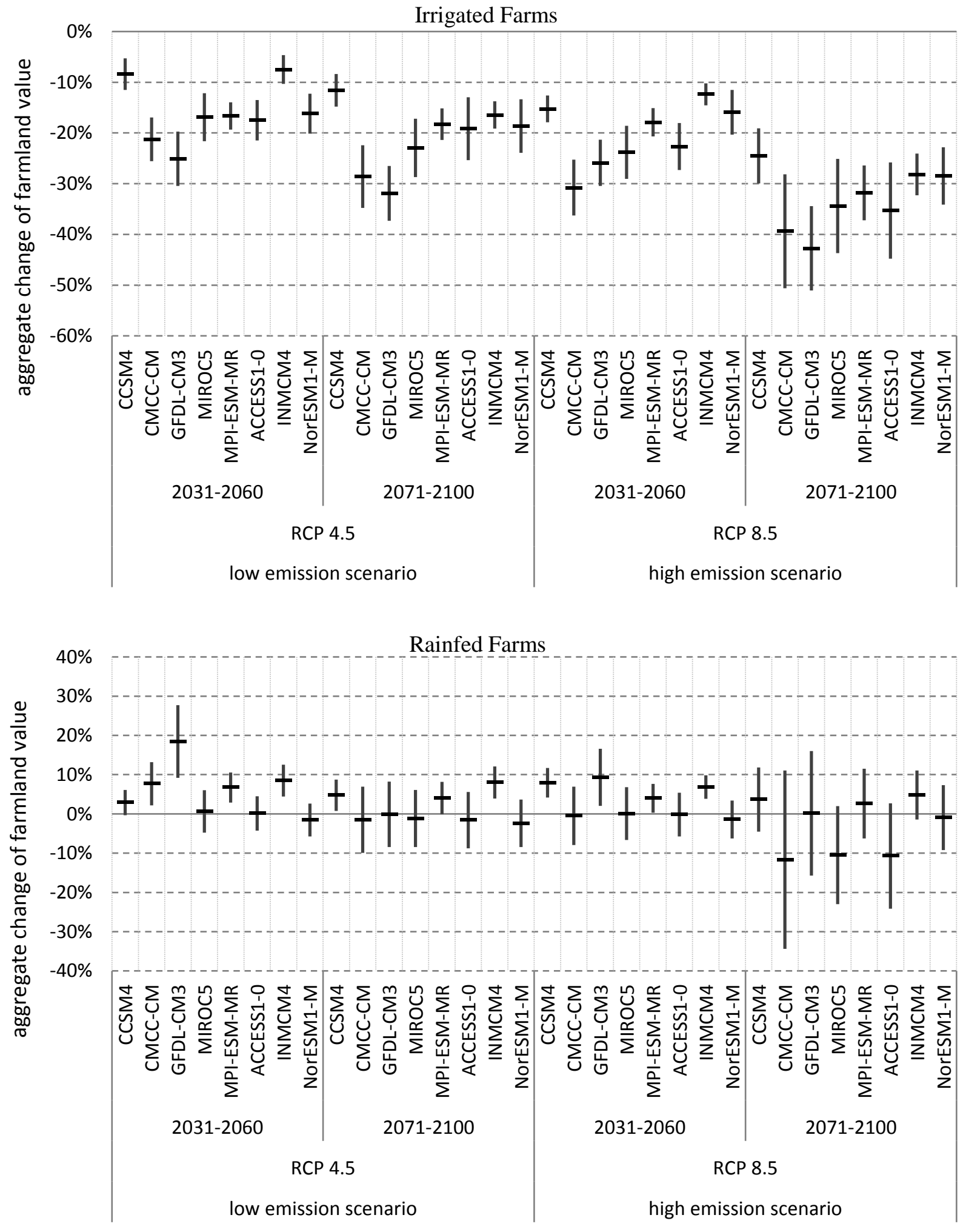

Note: Expected value and $95 \%$ bootstrap confidence intervals.

Fig. 5. Percentage change in Irrigated and Rainfed Farmland Values across Climate Scenarios. 


\section{Concluding Remarks}

Recent studies of the impact of climate change in Europe suggest that agricultural damage will be concentrated in the southern tier of the continent. Van Passel, Massetti and Mendelsohn (2016), project climate change impacts for Europe using 2071-2100 climate change projections to range from $-34 \%$ to $-71 \%$ of total land values. Most of these losses are concentrated in Italy because Italian farmland is very valuable and at the same time vulnerable to warming. The relevance of Italy in determining continental agricultural impacts indicates that further studies of Italian farms are needed.

This study contributes to this goal by greatly increasing the level granularity at which Italian farms are used compared to Van Passel, Massetti and Mendelsohn (2016). For the first time Italian farm-level data is used to estimate the relationship between climate and agricultural land values. Our sample of Italian farms covers all current major farming activities in Italy, including both crop and livestock farms and irrigated and rainfed farms. This study shows that climate is an important factor determining land value in Italy. Increasing spring temperature is beneficial while increasing summer temperature is detrimental for agricultural land value. Also important to mention is the beneficial impact of more precipitation in spring and summer. These results are consistent with Ricardian studies in Europe (Van Passel, Massetti and Mendelsohn, 2016) and crop studies (Olesen et al., 2011) but we find lower marginal impact of warming than Van Passel, Massetti and Mendelsohn (2016).

In general, the results show the importance of seasonal climate changes when measuring impacts and considering climate adaptation policies. Notably, if climate change models predict different effects by season, the seasonal variation will be important. Climate impacts are also likely to vary a great deal across Italian regions because the climate is very heterogeneous. For example, an increase in precipitation tends to be harmful in the northern region, but beneficial further south.

We analyse non marginal impacts for four different scenarios: medium versus long run and low versus high emission pathways. The impacts on farmland values are heterogeneous across Italian regions but generally negative, with aggregate farmland value impacts ranging from about $+1.5 \%$ to about $-15.8 \%$.

Non-marginal climate impacts of current agricultural production are, as expected, more detrimental with a high emission scenario, compared to a low emission scenario. This is especially 
true by the end of the century. However, the marginal climate effects in the near term are not evenly harmful. There is no doubt that some regions of Italy are more vulnerable than others. Southern Italy is consistently the most vulnerable whereas the results in the North vary a great deal. Especially, as one examines ever greater spatial detail, a great deal of uncertainty emerges.

One important result of this paper is that long term climate change impacts in Italy are likely to be harmful. However, compared to the results of previous analyses of all of Western Europe (Van Passel, Massetti and Mendelsohn, 2016), the harmful impacts in Italy may be smaller than previously thought. Further work is necessary to explain these differences. Further work is also necessary to reveal if similar divergences emerge when using very high resolution farm data in other countries and to understand what causes the different climate sensitivities of different farm types.

A major advantage of the Ricardian method is that it accounts for all the adaptations that are available today to Italian farmers. However, the method also does not analyse how adaptation is implemented and it does not take into account likely future changes in crop varieties and animal breeds, technology, prices, and investments. It is not known how these other changes might affect the climate sensitivity of farms. Constraints associated with future available water supplies were not included in the analysis. Finally, although the analysis looked at many climate model forecasts, it is not clear that the study included all possible future climate scenarios. An important further caveat, as in other econometric studies, concerns our inability to account for the positive effect of carbon fertilisation due to changes in $\mathrm{CO}_{2}$ concentrations, which are uniformly spread across the globe. Laboratory tests suggest that with a doubling of $\mathrm{CO}_{2}$ concentration productivity would increase by $10-30 \%$ and field test estimate a $15 \%$ productivity gain (Long et al., 2006, Leakey et $a l ., 2009)$. These productivity gains are commensurate with the estimated reduction of land values. 


\section{Bibliography}

Baltagi, H. B. (2013). Econometric Analysis of Panel Data, Fifth Edition. John Wiley \& Sons. UK.

Chatzopoulos, T. and Lippert C. (2016). Endogenous farm-type selection, endogenous irrigation, and spatial effects in Ricardian models of climate change, European Review of Agricultural Economics 43: 217-235.

Chatzopoulos, T. and Lippert, C. (2015). Adaptation and climate change impacts: a Structural Ricardian analysis of farm types in Germany. Journal of Agricultural Economics 66(2): 537-554.

Chow, G. C. (1960). Tests of equality between sets of coefficients in two linear regressions. Econometrica 28: 591-605.

Conley, T. G. (1999). GMM estimation with cross sectional dependence. Journal of Econometrics 92: 1-45.

Deschênes, O. and Greenstone, M. (2007). The economic impacts of climate change: Evidence from agricultural profits and random fluctuations in weather. American Economic Review 97: 354-385.

De Salvo, M., Raffaelli R. and Moser R. (2013). The impact of climate change on permanent crops in an Alpine region: A Ricardian analysis. Agricultural Systems 118: 23-32.

Di Falco, S., Veronesi, M. and Yesuf, M. (2011). Does adaptation to climate change provide food security? Micro perspective from Ethiopia. American Journal of Agricultural Economics 93: 829-846.

Eckertsen, H., Blombäck, K., Kätterer, T. and Nyman, P. (2001). Modelling C, N, water and heat dynamics in winter wheat under climate change in southern Sweden. Agriculture Ecosystems \& Environment 142: 617.

Ewert, F., Rounsevell, M.D.A., Reginster I., Metzger M.J. and Leemans R. (2005). Future scenarios of European agricultural land use. I. Estimating changes in crop productivity. Agriculture, Ecosystems and Environment 107: 101-116.

FAO/IIASA/ISRIC/ISS-CAS/JRC, (2012). Harmonized World Soil Database (version 1.2). FAO, Rome, Italy and IIASA, Laxenburg, Austria.

Fezzi, C. and Bateman I. (2015). The Impact of Climate Change on Agriculture: Nonlinear Effects and Aggregation Bias in Ricardian Models of Farmland Values, Journal of the Association of Environmental and Resource Economist 2(1): 57-92.

Harris, I., Jones, P.D., Osborn, T.J. and Lister, D.H., (2014). Updated high-resolution grids of monthly climatic observations. International Journal of Climatology 34: 623-642.

Hsiang, S., (2010). Temperatures and cyclones strongly associated with economic production in the Caribbean and Central America. PNAS 25: 15367-15372.

Iglesias, A., Quiroga S., Moneo M. and Garrote L. (2012). From climate change impacts to the development of adaptation strategies: challenges for agriculture in Europe. Climatic Change, 112: 143-168.

Italian National Institute for Statistics (ISTAT) (2013). Italia in cifre 2013, 34pp.

Kelly, D.L., Kolstad C.D. and Mitchell G.T. (2005). Adjustment costs from environmental change. Journal of Environmental Economics and Management 50: 468-495.

Kurukulasuriya, P., Kala N. and Mendelsohn R. (2011). Adaptation and Climate Change Impacts: A Structural Ricardian Model of Irrigation and Farm Income in Africa. Climate Change Economics 2: 149174.

Kurukulasuriya, P. and Mendelsohn R. (2008). Crop switching as a strategy for adapting to climate change. African Journal of Agricultural and Resource Economics 2: 105-126. 
Lang, G. (2007). Where are Germany's gains from Kyoto? Estimating the effects of global warming on agriculture. Climatic Change 84: 423-439.

Lippert, C., Krimly, T. and Aurbacher, J. (2009). A Ricardian analysis of the impact of climate change on agriculture in Germany. Climatic Change 97: 593-610.

Leakey, A. D. B., Ainsworth, E. A., Bernacchi, C. J., Rogers, A., Long, S. P. and Ort D. R. (2009). Elevated $\mathrm{CO}_{2}$ effects on plant carbon, nitrogen, and water relations: six important lessons from FACE. Journal of Experimental Botany 60(10): 2859-2876.

Long, S. P., Ainsworth, E. A., Leakey, A. D. B., Nösberger, J. and Ort D. R. (2006). Food for Thought: Lower-Than-Expected Crop Yield Stimulation with Rising $\mathrm{CO}_{2}$ Concentrations. Science 312(5782): 19181921.

Maddison, D. (2000). A hedonic analysis of agricultural land prices in England and Wales. European Review of Agricultural Economics 27: 519-532.

Massetti, E., Mendelsohn, R. and Chonabayashi, S. (2016). How Well Do Degree Days over the Growing Season Capture the Effect of Climate on Farmland Values? Energy Economics 60: 144-150.

Massetti, E. and Mendelsohn, R. (2011). The impact of climate change on US agriculture: a repeated crosssectional Ricardian analysis. In Dinar, A. and Mendelsohn, R. (eds.) Handbook on Climate Change and Agriculture, Vol. Cheltenham, UK, Northampton, MA, USA: Edward Elgar.

Massetti, E. and Mendelsohn, R. (2011). Estimating Ricardian Functions with Panel Data. Climate Change Economics, 2: 301-319.

Mela, G., Longhitano, D. and Povellato A. (2012). The evolution of land values in Italy. Does the influence of agricultural prices really matter? $\mathrm{N}^{\mathrm{o}} 122479,123^{\text {rd }}$ Seminar, February 2012, Dublin, Ireland, European Association of Agricultural Economists (EAAE).

Mendelsohn, R. and Dinar, A. (2009). Climate Change and Agriculture: An Economic Analysis of Global Impacts, Adaptation and Distributional Effects (Cheltenham, UK: Edward Elgar Publishing, 2009, p. 256).

Mendelsohn, R., Nordhaus, W. and Shaw, D. (1994). The impact of global warming on agriculture: A Ricardian analysis. American Economic Review 84: 753-771.

Moore, F. and Lobell, D. (2014). Adaptation potential of European agriculture in response to climate change. Nature Climate Change. 4: 610-614

Olesen, J.E. and Bindi, M. (2002). Consequences of climate change for European agricultural productivity, land use and policy. European Journal of Agronomy 16: 239-262.

Olesen, J.E., Trnka, M., Kersebaum, K.C., Skjelvåg, A.O., Seguin, B., Peltonen-Sainio, P., Rossi, F., Kozyra, J., Micale F. (2011). Impacts and adaptation of European crop production systems to climate change, European Journal of Agronomy 34(2): 96-112.

Palosuo, T., Kersebaum, K. C., Angulo, C., Hlavinka, P., Moriondo, M., Olesen, J. E., Patil, R. H., Ruget, F., Rumbaur, C., Takáč, J., Trnka, M., Bindi, M., and Çaldağ, B., (2011). Simulation of winter wheat yield and its variability in different climates of Europe: A comparison of eight crop growth models. European Journal of Agronomy 35: 103-114.

Porter, J.R., Soussana, J.F.; Fereres, E.; Long, S.; Mohren, F.; Peltonen-Sainio, P.; von Braun, J. (2013). European Perspectives: An agronomic science plan for food security in a changing climate. In: Hillel, D., Rosenzweig, C. (eds.), Imperial College Press, London, pp. 73-84.

Reidsma, P., Ewert, F., Lansink, A. O. and Leemans R. (2010). Adaptation to climate change and climate variability in European agriculture: The importance of farm level responses. European Journal of Agronomy 32: $91-102$. 
Ricardo, D. (1817). On the principles of political economy and taxation. Batoche Books, Ontaria.

Roy, S. N. (1957). Some Aspects of Multivariate Analysis. Wiley: New York.

Rötter, R.P., Carter, T.R., Olesen, J.E. and Porter, J.R. (2011a). Crop-climate models need an overhaul. Nature Climate Change 1: 175-177.

Rötter, R.P., Palosuo, T., Pirttioja, N.K., Dubrovsky, M., Salo, T., Fronzek, S., Aikasalo, R., Trnka, M., Ristolainen, A., Carter T.R. (2011b). What would happen to barley production in Finland if global warming exceeded $4^{\circ} \mathrm{C}$ ? A model-based assessment. European Journal of Agronomy 35(4): 205-214.

Rötter, R.P., Palosuo, T., Kersebaum, K. C., Angulo, C., Bindi, M., Ewert, F., Ferrise, R., Hlavinka, P., Moriondo, M., Nendel, C., Olesen, J. E., Patil, R. H., Ruget, F., Takáč, J., Trnka M. (2012). Simulation of spring barley yield in different climatic zones of Northern and Central Europe: A comparison of nine crop models. Field Crops Research 133: 23-36.

Schlenker, W., Hanemann, W.M. and Fisher, A.C. (2005). Will U.S. Agriculture Really Benefit from Global Warming? Accounting for Irrigation in the Hedonic Approach. The American Economic Review 95: 395406.

Schlenker, W., Hanemann, W.M. and Fisher, A. (2006). The impact of global warming on U.S. Agriculture: an econometric analysis of optimal growing conditions. The Review of Economics and Statistics 88: 113125.

Seo, S. N., and Mendelsohn, R. (2008a). A Ricardian Analysis of the Impact of Climate Change on South American Farms. Chilean Journal of Agricultural Research 68: 69-79.

Seo, S. N., and Mendelsohn, R. (2008b). Measuring Impacts and Adaptations to Climate Change: A Structural Ricardian Model of African Livestock Management. Agricultural Economics 38: 151-165.

Seo, S. N. and Mendelsohn, R. (2008c). Animal husbandry in Africa: Climate change impacts and adaptations. African Journal of Agricultural and Resource Economics 2: 65-82.

Timmins, C. (2006). Endogenous Land Use and the Ricardian Valuation of Climate Change. Environmental and Resource Economics 33: 119-142.

Vanschoenwinkel, J., R. Mendelsohn, and Van Passel, S., (2016). Do Western and Eastern Europe have the same agricultural climate response? Taking adaptive capacity into account. Global Environmental Change 41: 74-87.

Van Passel, S., Massetti, E. and Mendelsohn, R. (2016). A Ricardian Analysis of the Impact of Climate Change on European Agriculture. Environmental and Resource Economics, forthcoming.

Van Vuuren, D.P., Edmonds, J., Kainuma, M., Riahi, K., Thomson, A., Hibbard, K., Hurtt, G. C., Kram, T., et al. (2011). Representative Concentration Pathways: An overview. Climatic Change, Climatic Change 109: 5-31.

Wang, J., Mendelsohn, R., Dinar, A. and Huang, J. (2010). How Chinese farmers change crop choice to adapt to climate change. Climate Change Economics 1: 167-185

Zellner, A. (1962). An efficient method of estimating seemingly unrelated regression and tests for aggregation bias. Journal of American Statistical Association 57: 348-368.

Zhang, P., Zhang, J., and Chen, M. (2017). Economic Impacts of Climate Change on Agriculture: The Importance of Additional Climatic Variables Other than Temperature and Precipitation. Journal of Environmental Economics and Management 83: 8-31. 


\section{Appendices}

Table A1. Variables definitions

\begin{tabular}{|c|c|c|}
\hline Variable & Description & Source \\
\hline \multicolumn{3}{|c|}{$\underline{\text { Farm specific variables }}$} \\
\hline Farmland value & $\begin{array}{l}\text { The agricultural land is valued on the basis of prices (net of acquisition costs) applying in the } \\
\text { region for non-rented land of similar situation and quality sold for agricultural purposes. The } \\
\text { total value is divided by the utilized agricultural area. (Euro/ha) }\end{array}$ & INEA \\
\hline Farm size & Total agricultural area (ha) & INEA \\
\hline Rented farmland & Total leased land per total utilized agricultural land (ha/ha) & INEA \\
\hline Elevation & Mean level of farm elevation ( 000 Metres above sea level (MASL)) & INEA \\
\hline Latitude & Latitude $\left(^{\circ}\right)$ & INEA/ENEA/ISTAT \\
\hline Latitude & Longitude $\left(^{\circ}\right)$ & INEA/ENEA/ISTAT \\
\hline Slope index & $\begin{array}{l}\text { Index of the inclination of the farmland. Weighted average of the index associated to each lot } \\
\text { in the farmland. The maximum value of } 4 \text { indicates very steep areas, } 1 \text { is associated to flat } \\
\text { areas, } 2 \text { to moderate slope and } 3 \text { to medium slopes. We replaced the } 0 \text { (slope not declared) } \\
\text { with missing values. Farms reporting } 0 \text { are not geographically concentrated thus slope effects } \\
\text { not captured by these entries are likely to offset each other. }\end{array}$ & INEA \\
\hline Young farmer & $\begin{array}{l}\text { Dummy variable: } 1 \text { if farmer is younger than } 40 \text { years old (i.e. she/he is a young } \\
\text { entrepreneurs according to the Italian law), } 0 \text { otherwise. }\end{array}$ & INEA \\
\hline \multicolumn{3}{|c|}{ Municipality-specific climatic variables } \\
\hline Temp. winter & Average air temperature 1977-2007 December - February $\left({ }^{\circ} \mathrm{C}\right)$ & CRU \\
\hline Temp. spring & Average air temperature 1977-2007 March - May $\left({ }^{\circ} \mathrm{C}\right)$ & CRU \\
\hline Temp summer & Average air temperature $1977-2007$ June - August $\left({ }^{\circ} \mathrm{C}\right)$ & CRU \\
\hline Temp. autumn & Average air temperature 1977-2007 September - November $\left({ }^{\circ} \mathrm{C}\right)$ & CRU \\
\hline
\end{tabular}




\begin{tabular}{|c|c|c|}
\hline Prec. winter & Precipitation 1977-2007 December - February (cm/mo) & CRU \\
\hline Prec. spring & Precipitation 1977-2007 March - May (cm/mo) & CRU \\
\hline Prec. summer & Precipitation 1977-2007 June - August (cm/mo) & CRU \\
\hline Prec. autumn & Precipitation 1977-2007 September - November (cm/mo) & CRU \\
\hline \multicolumn{3}{|c|}{ Municipality-specific soil characteristics } \\
\hline$\%$ gravel & $\begin{array}{l}\text { Volume percentage gravel (materials in a soil larger than } 2 \mathrm{~mm} \text { ) in the topsoil (i.e. } 0-30 \mathrm{~cm} \text { ) } \\
\text { (\%vol) }\end{array}$ & World Soil database \\
\hline$\%$ sand & Weight percentage sand content in the topsoil (\%wt) & World Soil database \\
\hline Nutrient & $\begin{array}{l}\text { Cation exchange capacity (CEC) of soil. Measures the total nutrient fixing capacity of a soil } \\
(\mathrm{cmol} / \mathrm{kg})\end{array}$ & World Soil database \\
\hline $\mathrm{pH}$ & $\begin{array}{l}\mathrm{pH} \text { measured in a soil-water solution }(-\log (\mathrm{H}+)) \text {. It is a measure for the acidity and alkalinity } \\
\text { of the soil }\end{array}$ & World Soil database \\
\hline \multicolumn{3}{|c|}{ Municipality socio-economic and geographic variables } \\
\hline Population density & Total resident population density as of 09/10/2011 ( $000 \mathrm{cap} / \mathrm{km}^{2}$ ) & ISTAT \\
\hline Population growth & Percentage change in population density between 2001 and 2011 & ISTAT \\
\hline Housing density & Number of conventional dwellings/ total municipality area $\left({ }^{\circ} 000 / \mathrm{km}^{2}\right)$ in 2011 & ISTAT \\
\hline Hotel density & Number touristic establishments/ total municipality area $\left(\mathrm{km}^{2}\right) 2011$ & ISTAT \\
\hline Coastal city & Dummy variable: 1 if at least some of the municipality's territory is sea coast, 0 otherwise & \multirow{2}{*}{ ISTAT } \\
\hline \multirow{3}{*}{$\begin{array}{l}\text { Macro-regions and } \\
\text { Regional (NUTS2) } \\
\text { dummies }\end{array}$} & $\begin{array}{l}\text { NORTH: Aosta Valley; Piedmont; Lombardy; Trentino; Alto Adige; Veneto; Friuli Venezia } \\
\text { Giulia: Liguria: Emilia Romagna }\end{array}$ & \\
\hline & CENTRE: Tuscany; Marche; Umbria; Lazio & \multirow{2}{*}{ INEA } \\
\hline & SOUTH: Abruzzo; Molise; Campania; Calabria; Puglia; Basilicata; Sicily & \\
\hline
\end{tabular}


Table A2. Mean temperature $\left({ }^{\circ} \mathrm{C}\right)$ and precipitation $(10 \mathrm{~mm})$ : entire sample and subsamples

\begin{tabular}{|lccccccccccc|}
\hline & \multicolumn{9}{c}{ Temperature $\left({ }^{\circ} \mathbf{C}\right)$} & \multicolumn{4}{c|}{ Precipitation (10mm) } \\
\hline All farms & Nb obs. & year & Winter & Spring & Summer & Autumn & Year (mean) & Winter & Spring & Summer & Autumn \\
North & 44,736 & 12.495 & 4.625 & 11.109 & 20.763 & 13.487 & 7.453 & 7.103 & 7.240 & 6.051 & 9.461 \\
Centre & 21,166 & 10.413 & 1.842 & 9.651 & 19.027 & 11.128 & 9.145 & 7.298 & 9.179 & 9.306 & 10.863 \\
South & 8,743 & 13.184 & 5.554 & 11.522 & 21.428 & 14.238 & 6.581 & 6.653 & 6.100 & 4.320 & 9.301 \\
Crops & 14,827 & 15.061 & 8.051 & 12.946 & 22.849 & 16.412 & 5.552 & 7.090 & 5.145 & 2.425 & 7.554 \\
Livestock & 32,074 & 12.841 & 4.961 & 11.448 & 21.117 & 13.842 & 7.280 & 7.019 & 7.019 & 5.722 & 9.404 \\
Irrigated & 10,512 & 11.479 & 3.658 & 10.107 & 19.702 & 12.451 & 7.970 & 7.387 & 7.894 & 7.035 & 9.612 \\
Rainfed & 16,812 & 12.434 & 4.553 & 11.104 & 20.663 & 13.419 & 7.607 & 7.195 & 7.370 & 6.336 & 9.575 \\
\hline
\end{tabular}

Note: This Table shows the mean temperature and precipitation for each farm sub-sample, at which we evaluated the marginal effects of seasonal temperature and precipitation. 
Table A3. Log-linear regression of farmland value (Euro/ha) on climate and control variables with region fixed effects

\begin{tabular}{|c|c|c|}
\hline & Coefficient & Std. Err. \\
\hline Temp. winter & -0.320 & {$[0.230]$} \\
\hline Temp. winter squared & $0.027 *$ & {$[0.015]$} \\
\hline Temp. spring & $1.014 * * *$ & [0.331] \\
\hline Temp. spring squared & $-0.029 * *$ & {$[0.014]$} \\
\hline Temp. summer & $-2.663 * * *$ & [0.437] \\
\hline Temp. summer squared & $0.049 * * *$ & {$[0.010]$} \\
\hline Temp autumn & $1.547 *$ & [0.810] \\
\hline Temp autumn squared & $-0.046^{*}$ & {$[0.025]$} \\
\hline Prec. winter & $-0.483 * * *$ & [0.121] \\
\hline Prec. winter squared & $0.024 * * *$ & {$[0.006]$} \\
\hline Prec. spring & $0.497 * * *$ & [0.144] \\
\hline Prec. spring squared & $-0.029 * * *$ & [0.009] \\
\hline Prec. summer & $0.244 * * *$ & {$[0.078]$} \\
\hline Prec. summer squared & $-0.008 *$ & [0.004] \\
\hline Prec. autumn & $-0.216 * * *$ & [0.066] \\
\hline Prec. autumn squared & $0.007 * * *$ & {$[0.002]$} \\
\hline$\%$ gravel & $-0.028 * * *$ & {$[0.005]$} \\
\hline$\%$ sand & 0.001 & {$[0.002]$} \\
\hline $\mathrm{pH}$ & $0.501 * * *$ & [0.155] \\
\hline pH squared & $-0.037 * * *$ & {$[0.013]$} \\
\hline Nutrient & $0.009 * *$ & {$[0.003]$} \\
\hline Young farmer & $0.037 * * *$ & {$[0.006]$} \\
\hline Farm size & $-0.001 * * *$ & {$[0.0002]$} \\
\hline Rented farmland & $-0.045^{* * *}$ & {$[0.012]$} \\
\hline Elevation & $-0.129 * * *$ & {$[0.007]$} \\
\hline Slope index & $0.219 * * *$ & {$[0.040]$} \\
\hline Slope index squared & $-0.058 * * *$ & {$[0.014]$} \\
\hline Population density & $0.025 * * *$ & {$[0.006]$} \\
\hline Population growth & $0.823 * * *$ & {$[0.071]$} \\
\hline Coastal city & 0.049 & {$[0.030]$} \\
\hline Housing density & -0.0002 & {$[0.015]$} \\
\hline Hotel density & $0.025 * * *$ & [0.009] \\
\hline Latitude & $-0.162 * * *$ & {$[0.026]$} \\
\hline Longitude & $-0.104 * * *$ & {$[0.015]$} \\
\hline Constant & $31.247 * * *$ & {$[5.000]$} \\
\hline Observations & \multirow{2}{*}{\multicolumn{2}{|c|}{$\begin{array}{c}44,736 \\
0.638\end{array}$}} \\
\hline Adjusted R-squared & & \\
\hline
\end{tabular}

Note: The coefficients and the standard errors are corrected for spatial autocorrelation (Conley, 1999). Region fixed effects not shown. *** $\mathrm{p}<0.01, * * \mathrm{p}<0.05,{ }^{*} \mathrm{p}<0.1$ 
Table A4. Log-linear regressions of farmland value (Euro/ha) for farms with only crops and only livestock with regional fixed effects

\begin{tabular}{|c|c|c|c|c|}
\hline & \multicolumn{2}{|c|}{ [1] Crops Only } & \multicolumn{2}{|c|}{ [2] Livestock Only } \\
\hline & Coefficient & Std. Err. & Coefficient & Std. Err. \\
\hline Temp. winter & $-0.788 * * *$ & {$[0.241]$} & -0.090 & {$[0.206]$} \\
\hline Temp. winter squared & $0.045 * * *$ & [0.016] & 0.010 & {$[0.014]$} \\
\hline Temp. spring & $0.679 * *$ & {$[0.320]$} & 0.235 & [0.297] \\
\hline Temp. spring squared & -0.019 & {$[0.015]$} & 0.011 & {$[0.015]$} \\
\hline Temp. summer & $-2.504 * * *$ & {$[0.509]$} & $-0.893 *$ & {$[0.515]$} \\
\hline Temp. summer squared & $0.039 * * *$ & [0.012] & 0.018 & [0.012] \\
\hline Temp autumn & $2.712 * * *$ & {$[0.860]$} & 0.565 & {$[0.710]$} \\
\hline Temp autumn squared & $-0.065 * *$ & [0.026] & -0.034 & {$[0.021]$} \\
\hline Prec. winter & $-0.437 * * *$ & {$[0.114]$} & 0.057 & {$[0.126]$} \\
\hline Prec. winter squared & $0.025 * * *$ & {$[0.005]$} & 0.004 & {$[0.007]$} \\
\hline Prec. spring & 0.209 & [0.141] & $0.518 * * *$ & {$[0.168]$} \\
\hline Prec. spring squared & -0.005 & [0.009] & $-0.043 * * *$ & [0.008] \\
\hline Prec. summer & $0.411 * * *$ & [0.099] & 0.011 & {$[0.084]$} \\
\hline Prec. summer squared & $-0.020 * * *$ & {$[0.005]$} & $0.007 *$ & {$[0.004]$} \\
\hline Prec. autumn & $-0.136^{*}$ & {$[0.075]$} & $-0.299 * * *$ & [0.114] \\
\hline Prec. autumn squared & 0.001 & [0.003] & $0.010^{* *}$ & [0.004] \\
\hline$\%$ gravel & $-0.021 * * *$ & {$[0.005]$} & $-0.029 * * *$ & [0.004] \\
\hline$\%$ sand & $0.006 * * *$ & [0.002] & $-0.003 *$ & [0.002] \\
\hline $\mathrm{pH}$ & 0.104 & {$[0.124]$} & $0.577 * *$ & {$[0.251]$} \\
\hline pH squared & -0.008 & [0.011] & $-0.042 * *$ & {$[0.020]$} \\
\hline Nutrient & $0.009 * *$ & {$[0.004]$} & $0.013 * *$ & {$[0.006]$} \\
\hline Young farmer & $0.040 * * *$ & [0.009] & $0.030 * *$ & {$[0.012]$} \\
\hline Farm size & $-0.001 * * *$ & {$[0.000]$} & $-0.001 * * *$ & {$[0.000]$} \\
\hline Rented farmland & $0.024 * *$ & {$[0.010]$} & $-0.084 * * *$ & [0.018] \\
\hline Elevation & $-0.116 * * *$ & {$[0.012]$} & $-0.087 * * *$ & [0.006] \\
\hline Slope index & $0.353 * * *$ & {$[0.050]$} & $-0.071 *$ & [0.041] \\
\hline Slope index squared & $-0.094 * * *$ & {$[0.017]$} & 0.021 & {$[0.015]$} \\
\hline Population density & $0.018 * * *$ & [0.006] & $0.103 * * *$ & [0.018] \\
\hline Population growth & $0.819 * * *$ & [0.063] & $0.559 * * *$ & [0.086] \\
\hline Coastal city & $0.087 * *$ & {$[0.034]$} & $-0.068 * *$ & {$[0.031]$} \\
\hline Housing density & 0.003 & {$[0.013]$} & $-0.171 * * *$ & {$[0.038]$} \\
\hline Hotel density & $0.022 * *$ & [0.009] & $0.043 * * *$ & {$[0.014]$} \\
\hline Latitude & $-0.103 * * *$ & {$[0.026]$} & $-0.138 * * *$ & {$[0.026]$} \\
\hline Longitude & $-0.087 * * *$ & [0.013] & $-0.073 * * *$ & [0.018] \\
\hline Constant & $22.026^{* * *}$ & [4.717] & $19.591 * * *$ & [4.732] \\
\hline Observations & & & & \\
\hline Adjusted R-squared & & & & \\
\hline
\end{tabular}

Notes: The coefficients and the standard errors are corrected for spatial autocorrelation (Conley, 1999). Region fixed effects not shown. *** $\mathrm{p}<0.01$, ** $\mathrm{p}<0.05$, * $\mathrm{p}<0.1$. 
Table A5. Log-linear regressions of farmland value (Euro/ha) for irrigated farms and rainfed farms with regional fixed effects

\begin{tabular}{|c|c|c|c|c|}
\hline & \multicolumn{2}{|c|}{ [1] Irrigated } & \multicolumn{2}{|c|}{ [2] Rainfed } \\
\hline & coeff. & st.err. & coeff. & st.err \\
\hline Temp. winter & $-0.831 * * *$ & {$[0.281]$} & $0.793 * * *$ & {$[0.246]$} \\
\hline Temp. winter squared & 0.026 & {$[0.019]$} & $-0.047 * * *$ & [0.018] \\
\hline Temp. spring & -0.311 & {$[0.494]$} & $1.651 * * *$ & {$[0.358]$} \\
\hline Temp. spring squared & 0.020 & {$[0.024]$} & $-0.061 * * *$ & {$[0.013]$} \\
\hline Temp. summer & -0.829 & {$[0.974]$} & 0.237 & [0.519] \\
\hline Temp. summer squared & -0.001 & {$[0.022]$} & -0.006 & {$[0.012]$} \\
\hline Temp autumn & $2.353 * *$ & {$[1.006]$} & $-3.279 * * *$ & [0.906] \\
\hline Temp autumn squared & -0.042 & {$[0.030]$} & $0.100 * * *$ & {$[0.027]$} \\
\hline Prec. winter & $-0.425 * * *$ & {$[0.153]$} & $-0.647 * * *$ & [0.116] \\
\hline Prec. winter squared & $0.020 * * *$ & {$[0.007]$} & $0.041 * * *$ & [0.007] \\
\hline Prec. spring & $0.400 * *$ & {$[0.160]$} & $0.838 * * *$ & {$[0.113]$} \\
\hline Prec. spring squared & -0.014 & [0.009] & $-0.055^{* * *}$ & [0.007] \\
\hline Prec. summer & $0.291 * * *$ & {$[0.106]$} & -0.117 & {$[0.087]$} \\
\hline Prec. summer squared & $-0.013 * *$ & {$[0.005]$} & $0.015^{* * *}$ & {$[0.005]$} \\
\hline Prec. autumn & -0.098 & {$[0.111]$} & $-0.335^{* * *}$ & {$[0.054]$} \\
\hline Prec. autumn squared & -0.0004 & {$[0.004]$} & $0.012 * * *$ & {$[0.002]$} \\
\hline$\%$ gravel & -0.008 & {$[0.005]$} & $-0.018 * * *$ & {$[0.004]$} \\
\hline$\%$ sand & $0.003^{*}$ & [0.002] & $0.005 * * *$ & {$[0.001]$} \\
\hline $\mathrm{pH}$ & 0.078 & {$[0.147]$} & -0.144 & [0.104] \\
\hline $\mathrm{pH}$ squared & -0.002 & {$[0.013]$} & $0.015^{*}$ & {$[0.008]$} \\
\hline Nutrient & 0.001 & {$[0.003]$} & $0.006 * *$ & {$[0.003]$} \\
\hline Young farmer & $0.058 * * *$ & {$[0.010]$} & 0.014 & {$[0.011]$} \\
\hline Farm size & $-0.001 * * *$ & {$[0.0002]$} & $-0.001 * * *$ & [0.0001] \\
\hline Rented farmland & $0.050 * * *$ & {$[0.015]$} & $-0.017 *$ & [0.010] \\
\hline Elevation & $-0.092 * * *$ & {$[0.011]$} & $-0.071 * * *$ & {$[0.006]$} \\
\hline Slope index & $0.522 * * *$ & {$[0.058]$} & $0.182 * * *$ & {$[0.040]$} \\
\hline Slope index squared & $-0.161 * * *$ & {$[0.027]$} & $-0.026 * *$ & {$[0.013]$} \\
\hline Population density & $0.015^{* * *}$ & {$[0.005]$} & $0.056^{* * *}$ & {$[0.013]$} \\
\hline Population growth & $0.496 * * *$ & {$[0.070]$} & $0.782 * * *$ & {$[0.090]$} \\
\hline Coastal city & $0.135 * * *$ & {$[0.041]$} & $-0.045^{* * *}$ & {$[0.018]$} \\
\hline Housing density & 0.002 & {$[0.009]$} & $-0.084 * * *$ & {$[0.027]$} \\
\hline Hotel density & 0.016 & {$[0.013]$} & $0.033 * * *$ & {$[0.008]$} \\
\hline Latitude & $-0.156 * * *$ & {$[0.035]$} & $-0.058 * *$ & [0.024] \\
\hline Longitude & $-0.070 * * *$ & {$[0.025]$} & $-0.075^{* * *}$ & {$[0.015]$} \\
\hline Constant & $13.368 * *$ & {$[5.984]$} & $25.908 * * *$ & [5.230] \\
\hline Observations & & & & \\
\hline Adjusted R-squared & & & & \\
\hline
\end{tabular}

Notes: The coefficients and the standard errors are corrected for spatial autocorrelation (Conley, 1999). Region fixed effects not shown. $* * * \mathrm{p}<0.01, * * \mathrm{p}<0.05, * \mathrm{p}<0.1$. 
Table A6. Climate models overview

\begin{tabular}{lll} 
Acronym & Model full name & Source (Institution) \\
\hline ACCESS1-0 & $\begin{array}{l}\text { Australian Community Climate and Earth System } \\
\text { Simulator }\end{array}$ & $\begin{array}{l}\text { CSIRO (Commonwealth Scientific and Industrial Research } \\
\text { Organisation, Australia), and BOM (Bureau of Meteorology, } \\
\text { Australia) }\end{array}$ \\
\hline CCSM4 & Community Climate System Model & National Center for Atmospheric Research (NCAR), USA \\
\hline CMCC-CM & $\begin{array}{l}\text { Centro Euro-Mediterraneo sui Cambiamenti } \\
\text { Climatici Climate Model }\end{array}$ & Centro Euro-Mediterraneo sui Cambiamenti Climatici, Italy \\
\hline GFDL-CM3 & $\begin{array}{l}\text { Geophysical Fluid Dynamics Laboratory Climate } \\
\text { Model }\end{array}$ & Geophysical Fluid Dynamics Laboratory, USA \\
\hline INMCM4 & $\begin{array}{l}\text { Institute of Numerical Mathematics Climate Model } \\
\text { MIROC5 }\end{array}$ & $\begin{array}{l}\text { Institute of Numerical Mathematics, Russian Academy of Sciences, } \\
\text { Russia }\end{array}$ \\
\hline MPI-ESM-MR & $\begin{array}{l}\text { MPI Earth System Model running on medium } \\
\text { resolution grid }\end{array}$ & Atmosphere and Ocean Research Institute, University of Tokyo, Japan \\
\hline NorESM1-M & The Norwegian Earth System Model & Max Planck Institute for Meteorology (MPI-M), Germany \\
\hline
\end{tabular}




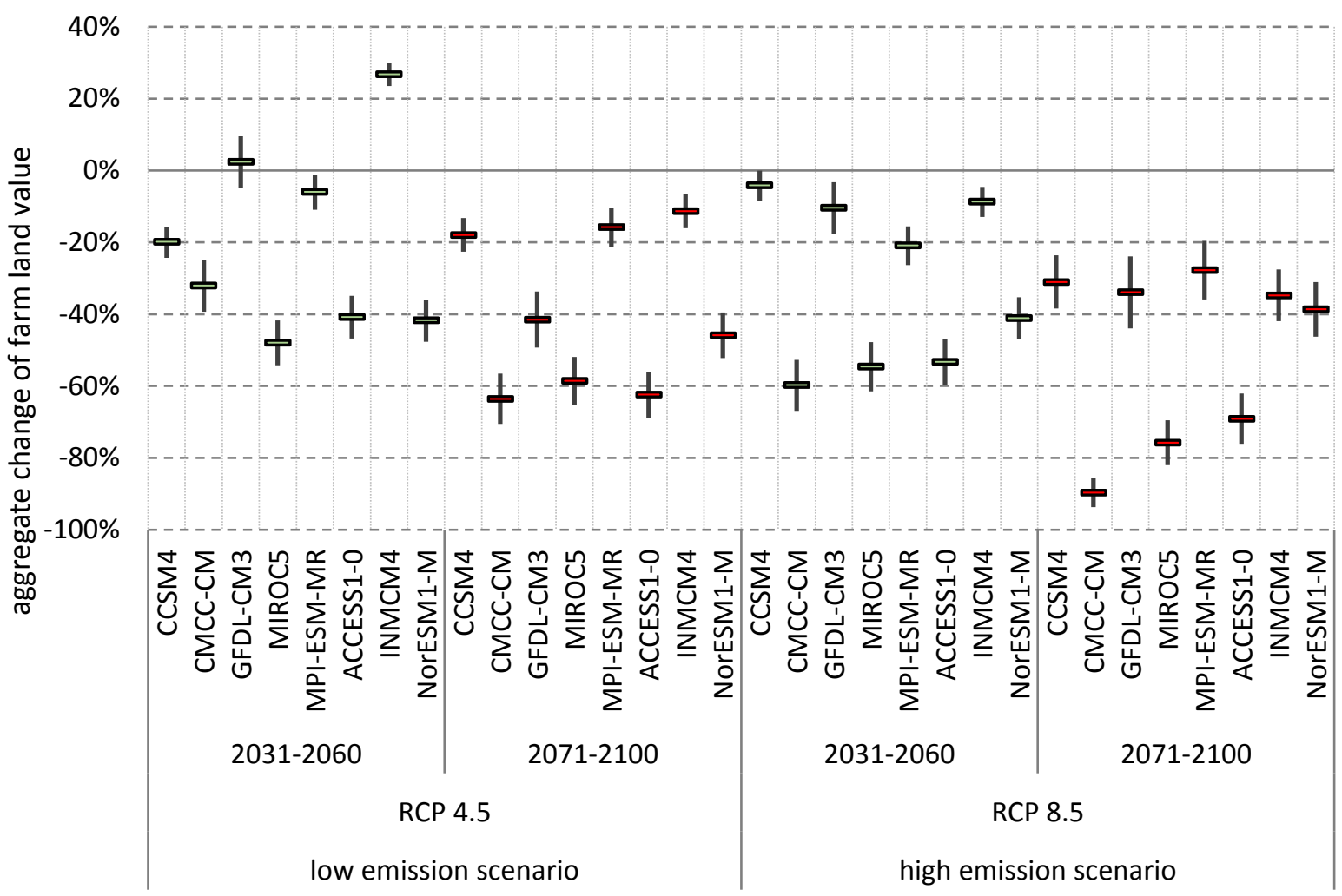

Fig. A1. Climate change impact on farmland values in Alto Adige

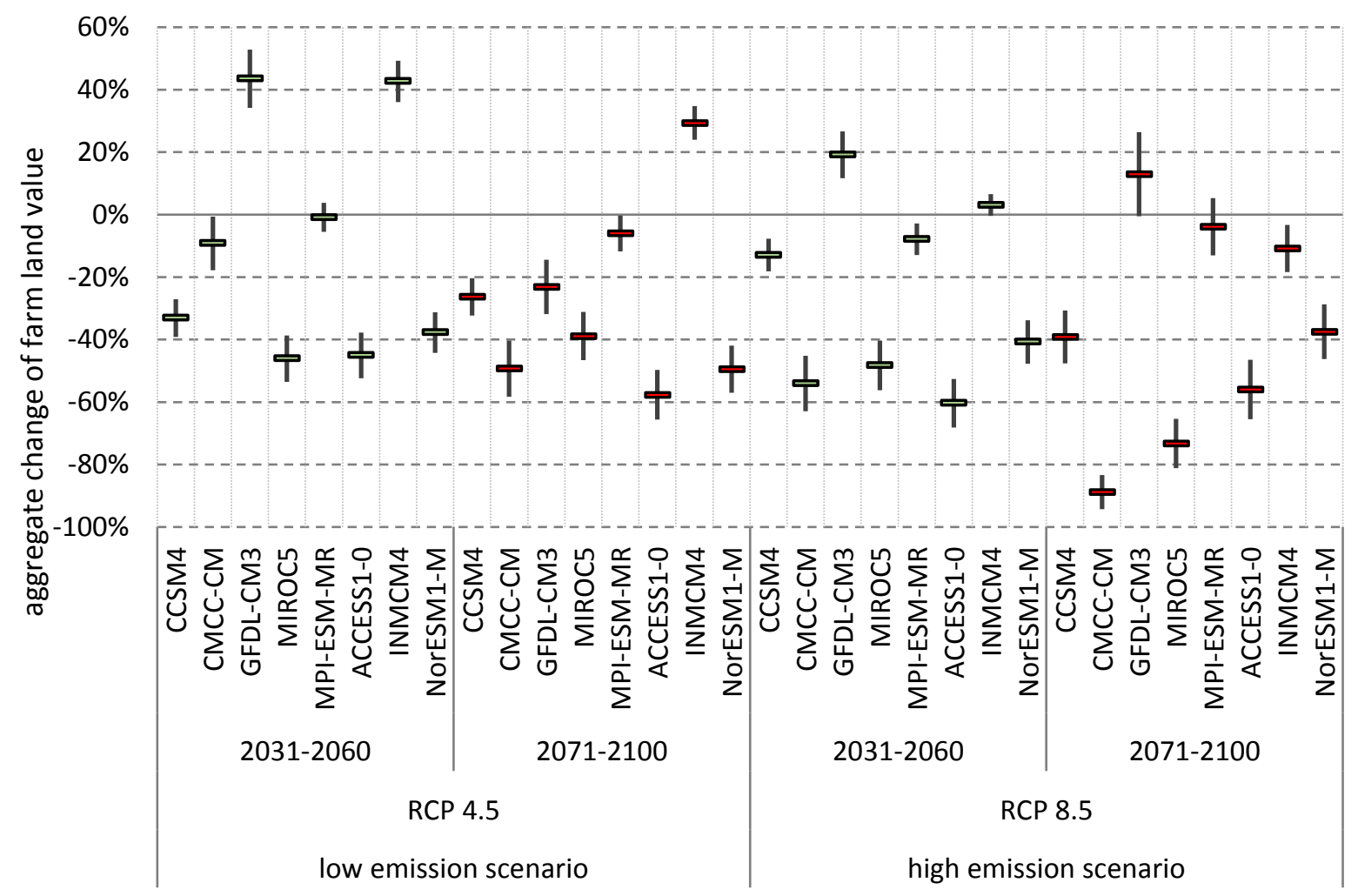

Fig. A2. Climate change impact on farmland values in Aosta Valley 


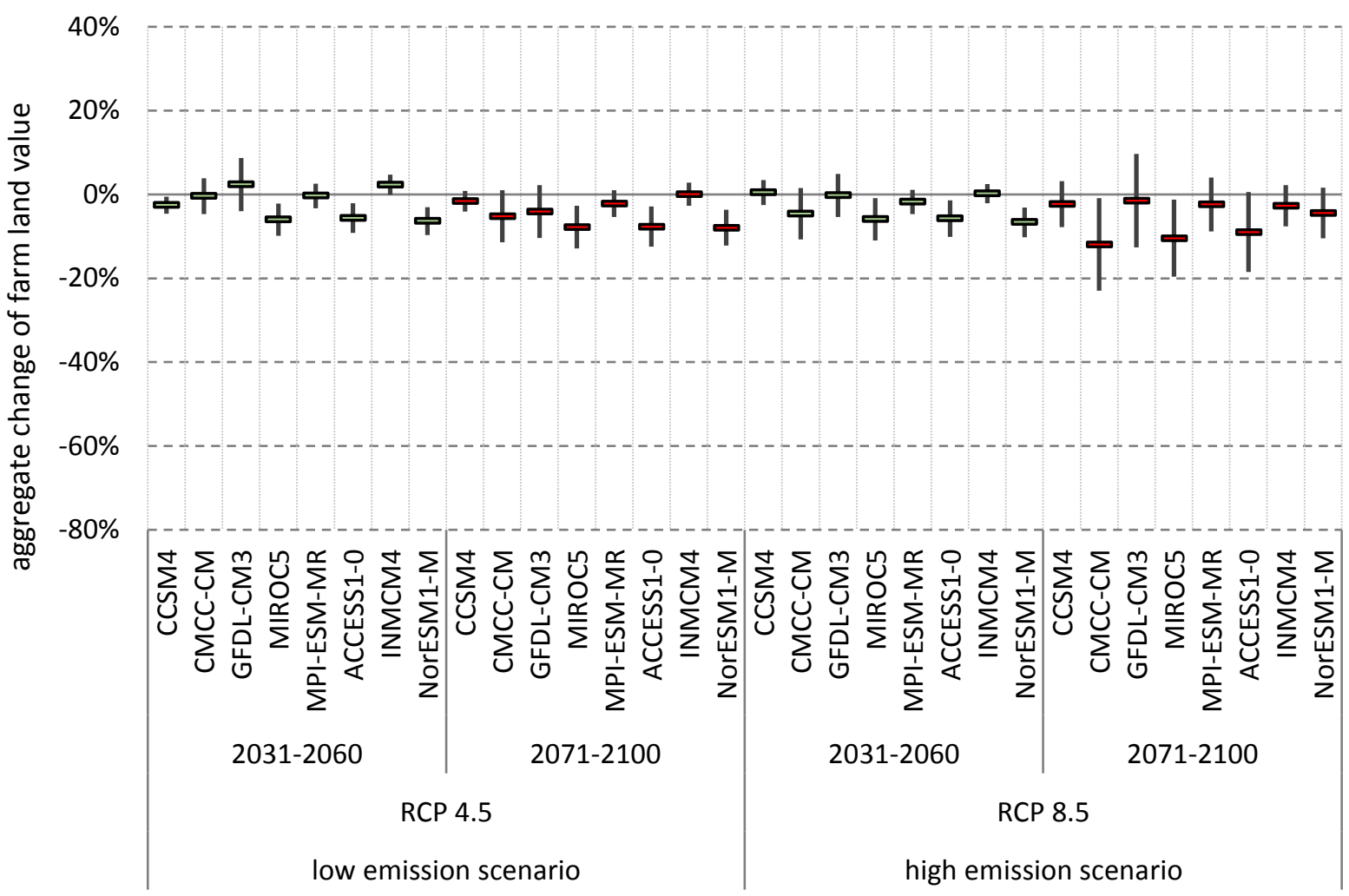

Fig. A3. Climate change impact on farmland values in Emilia Romagna

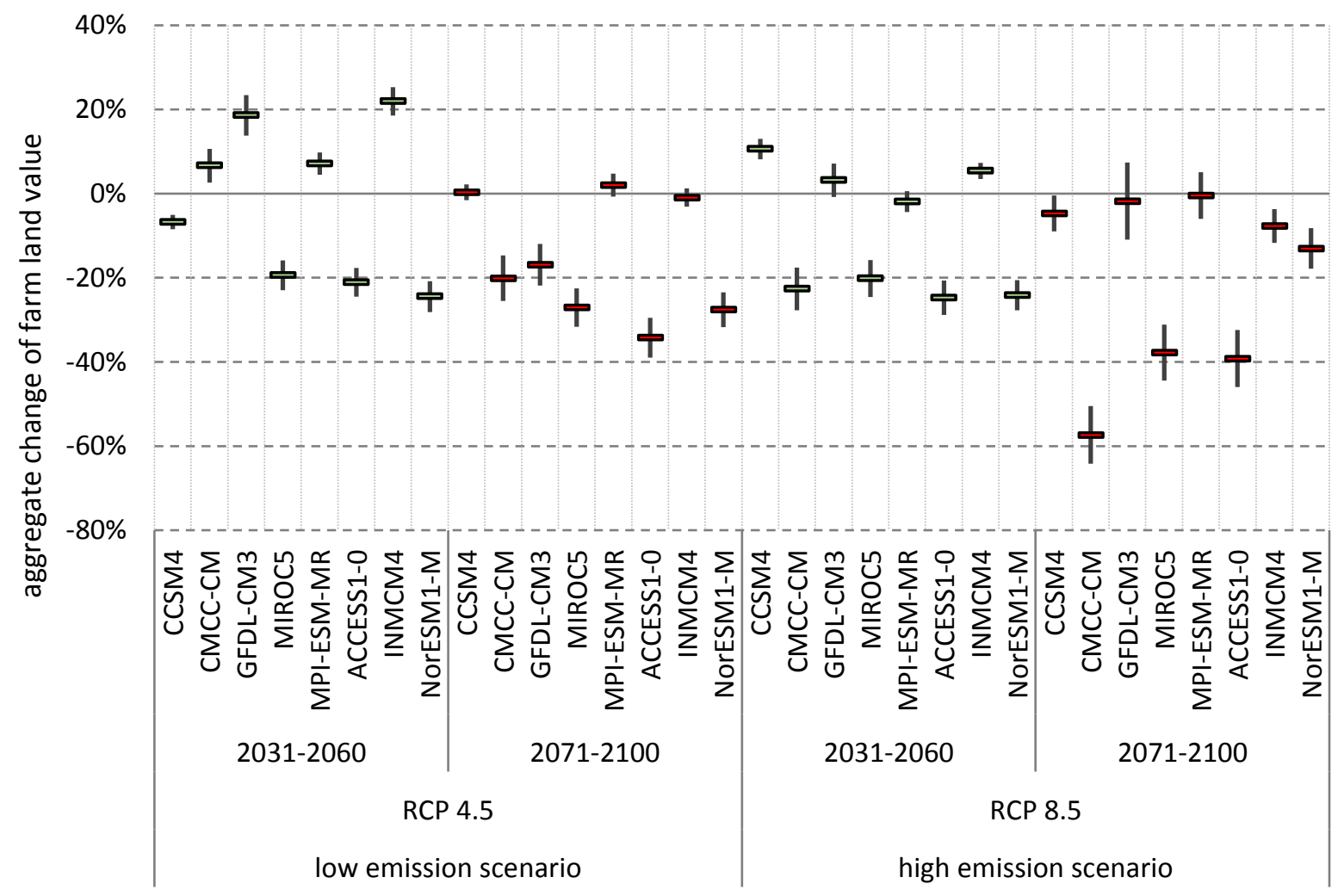

Fig. A4. Climate change impact on farmland values in Friuli Venezia Giulia 


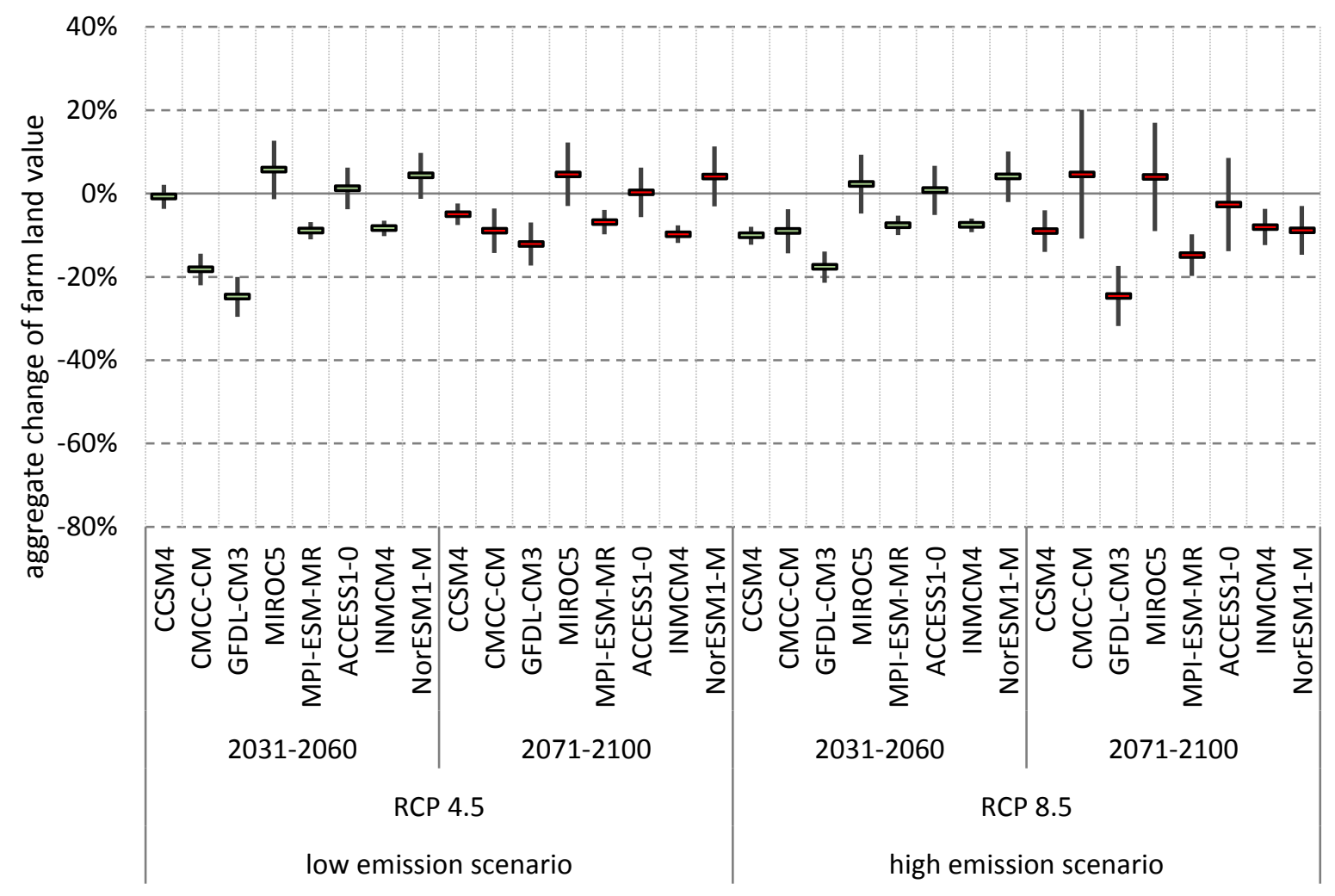

Fig. A5. Climate change impact on farmland values in Liguria

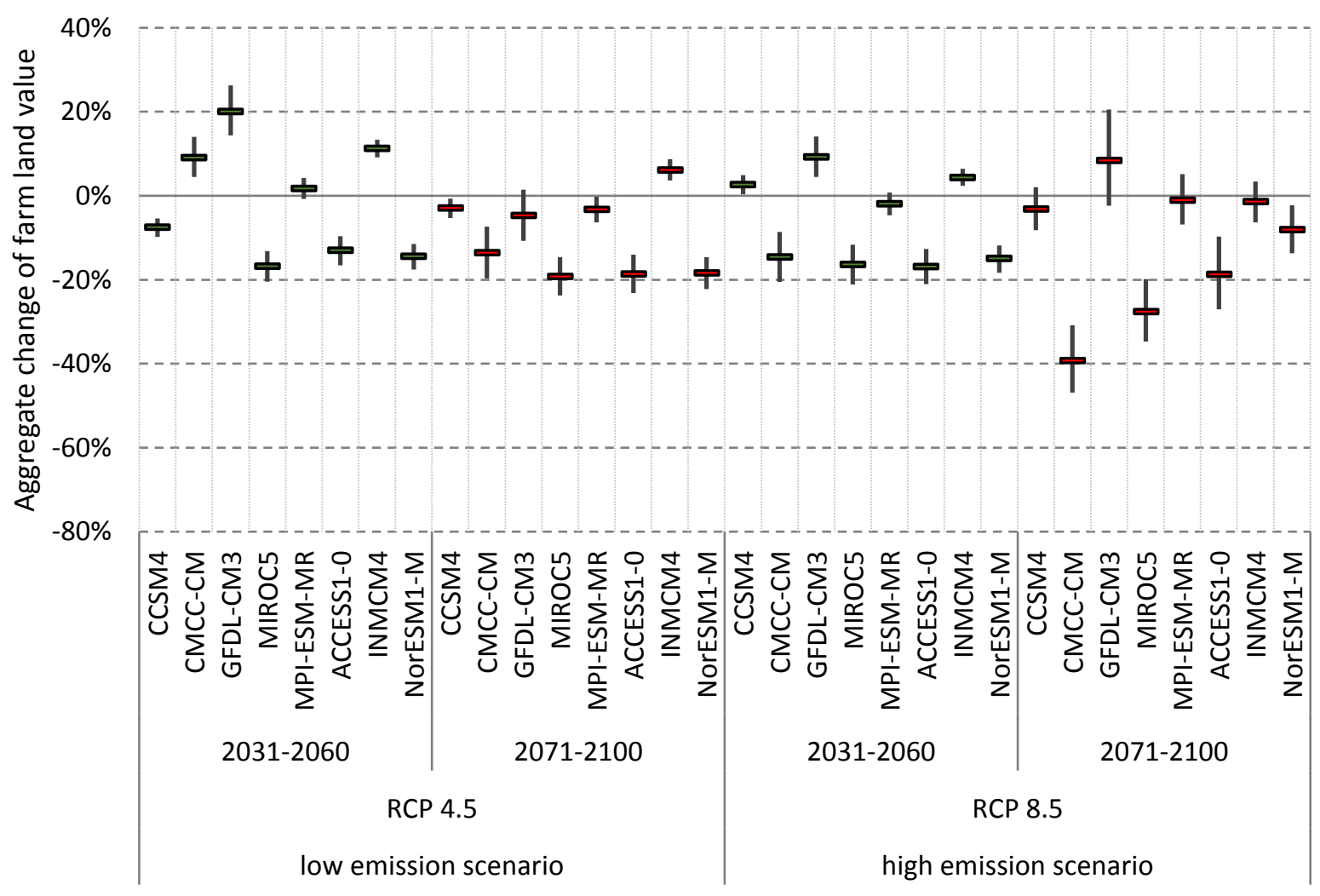

Fig. A6. Climate change impact on farmland values in Lombardy 


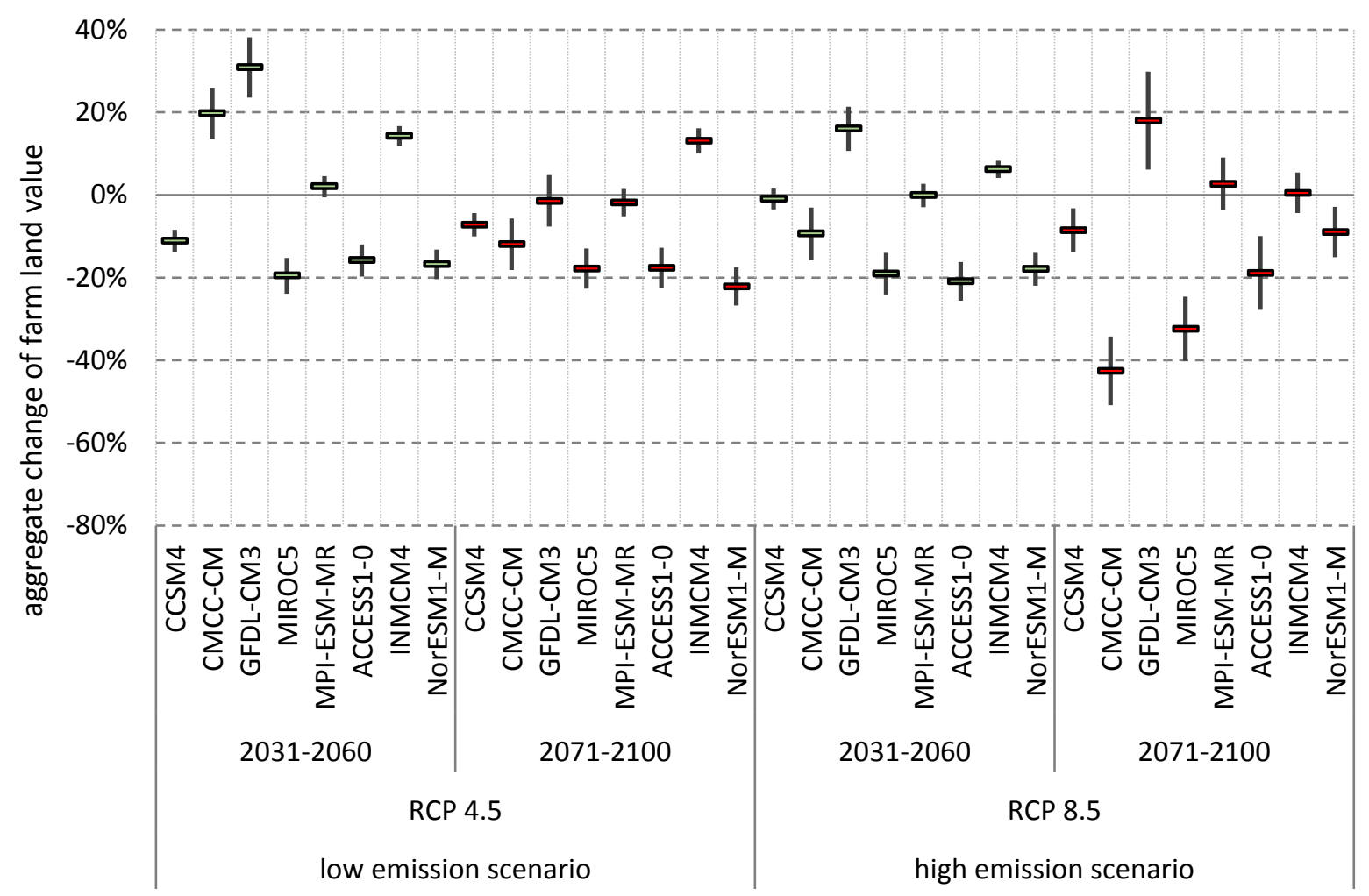

Fig. A7. Climate change impact on farmland values in Piedmont

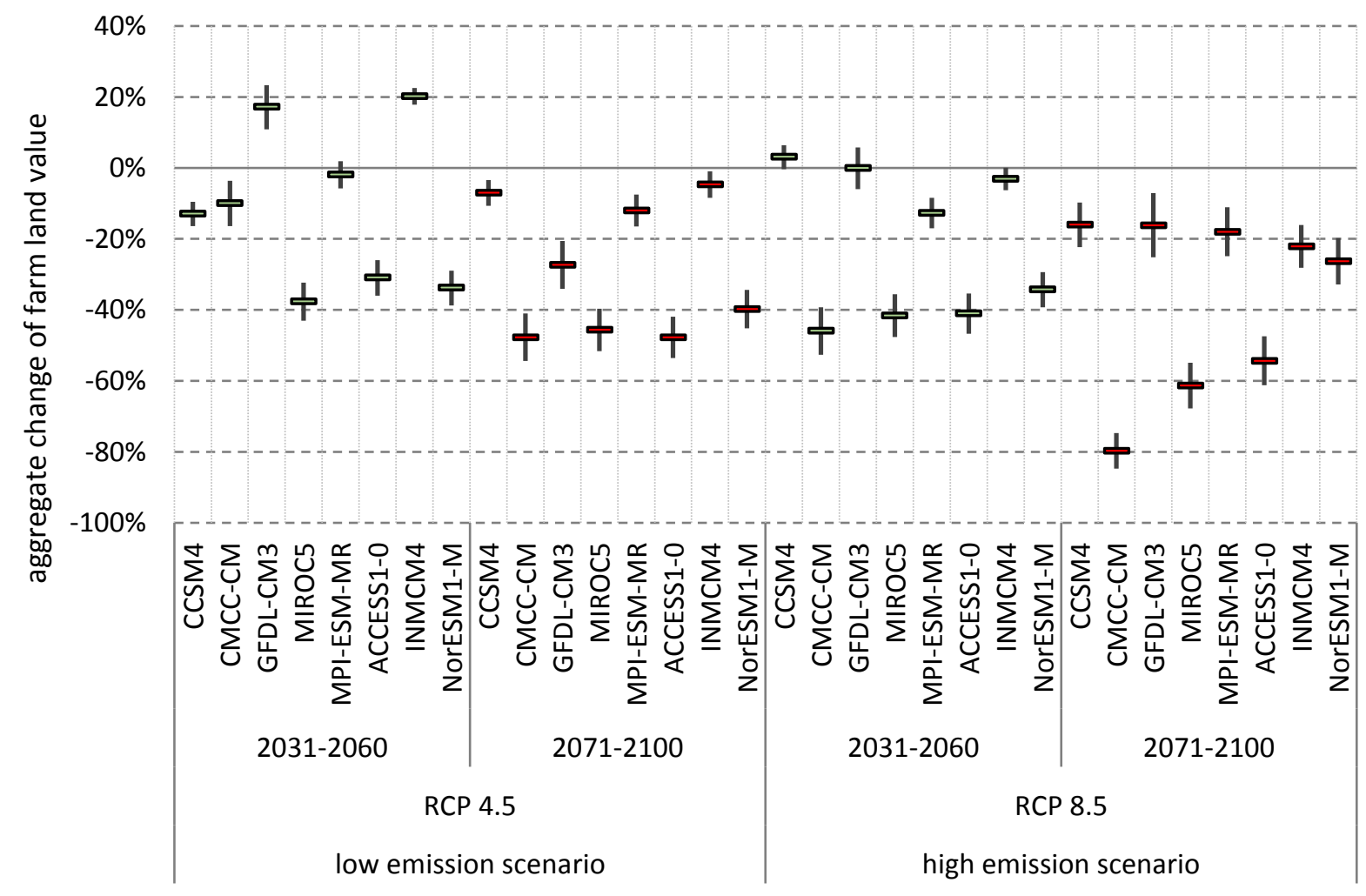

Fig. A8. Climate change impact on farmland values in Trentino 


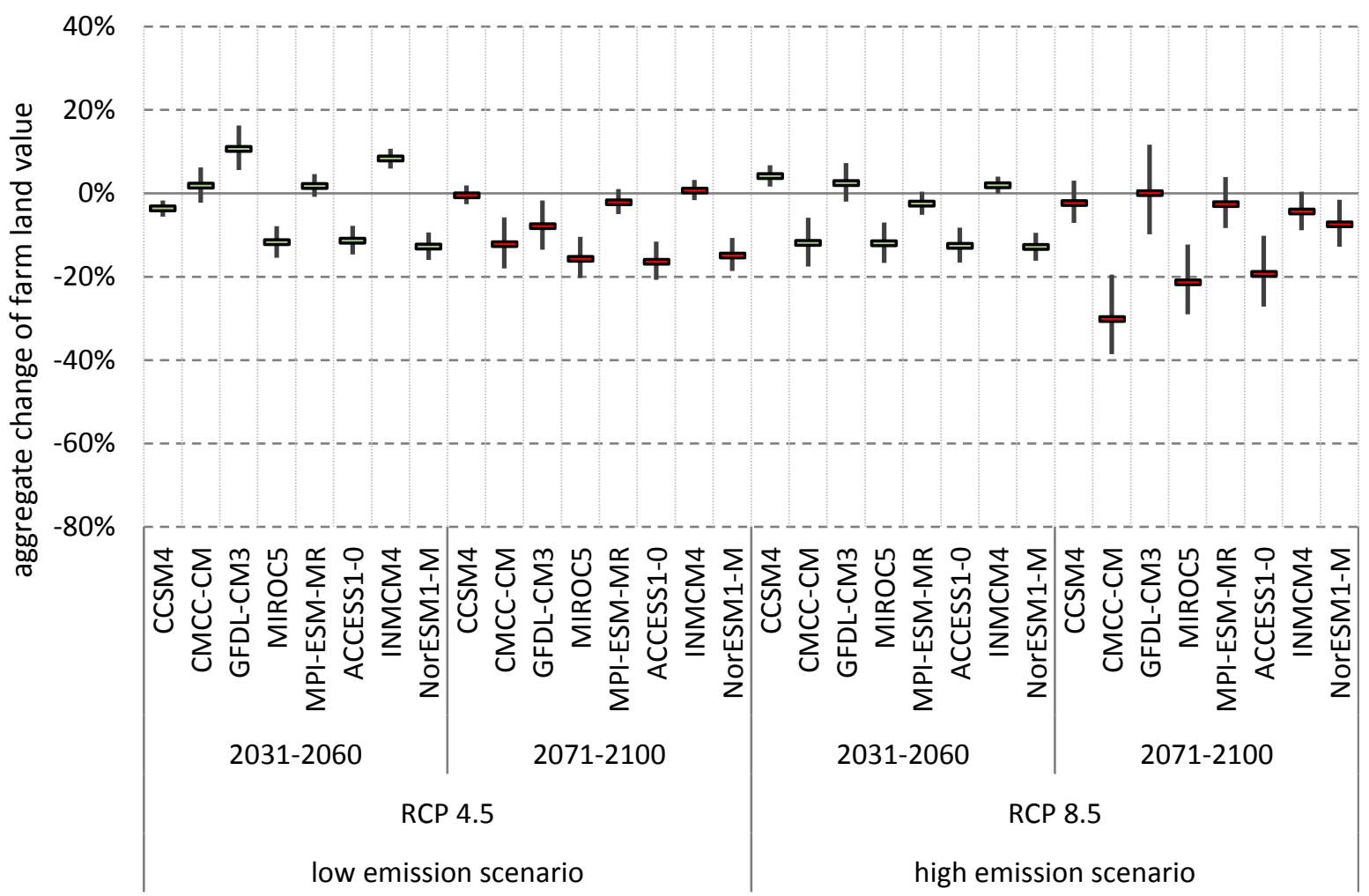

Fig. A9. Climate change impact on farmland values in Veneto

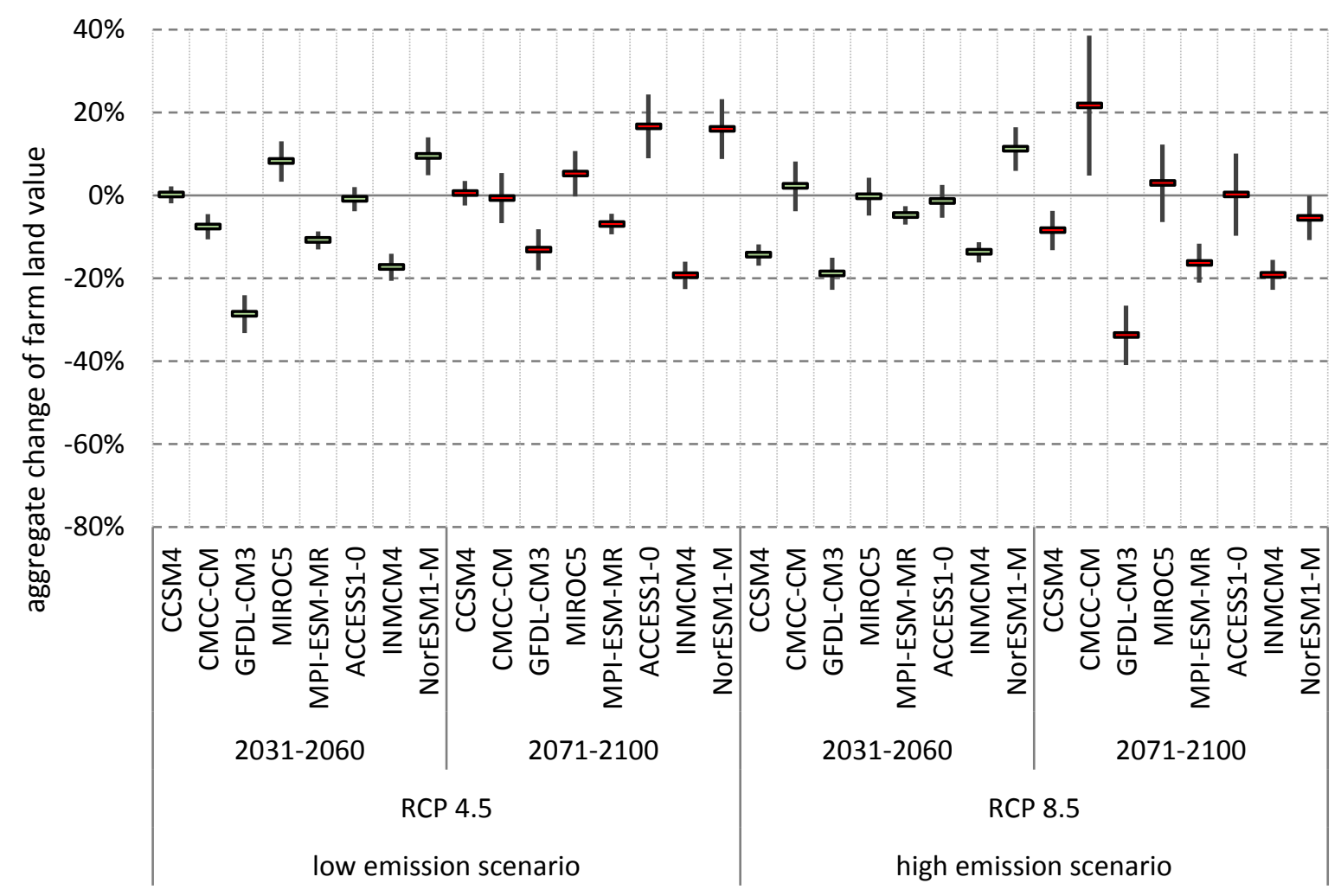

Fig. A10. Climate change impact on farmland values in Lazio 


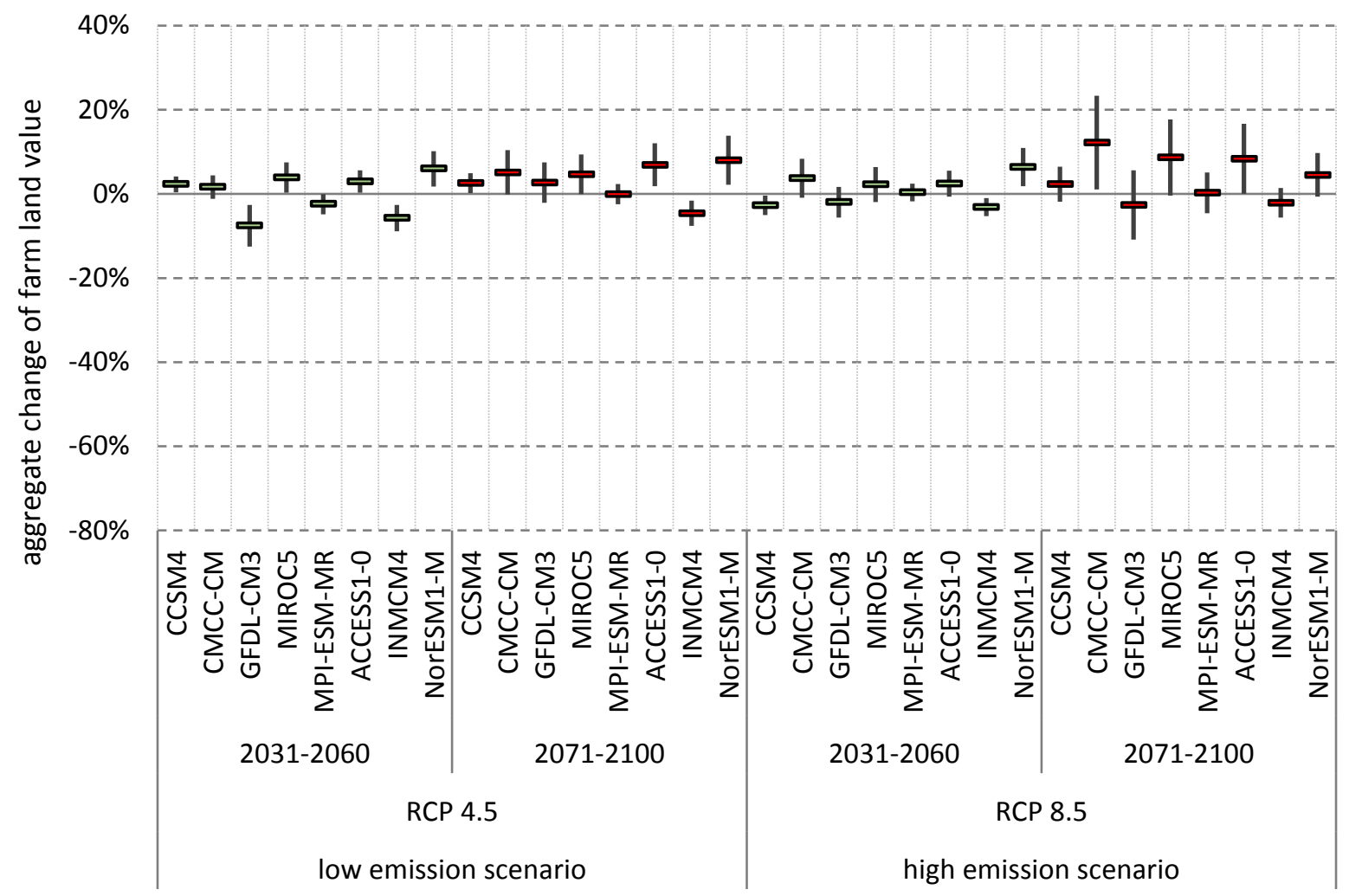

Fig. A11. Climate change impact on farmland values in Marche

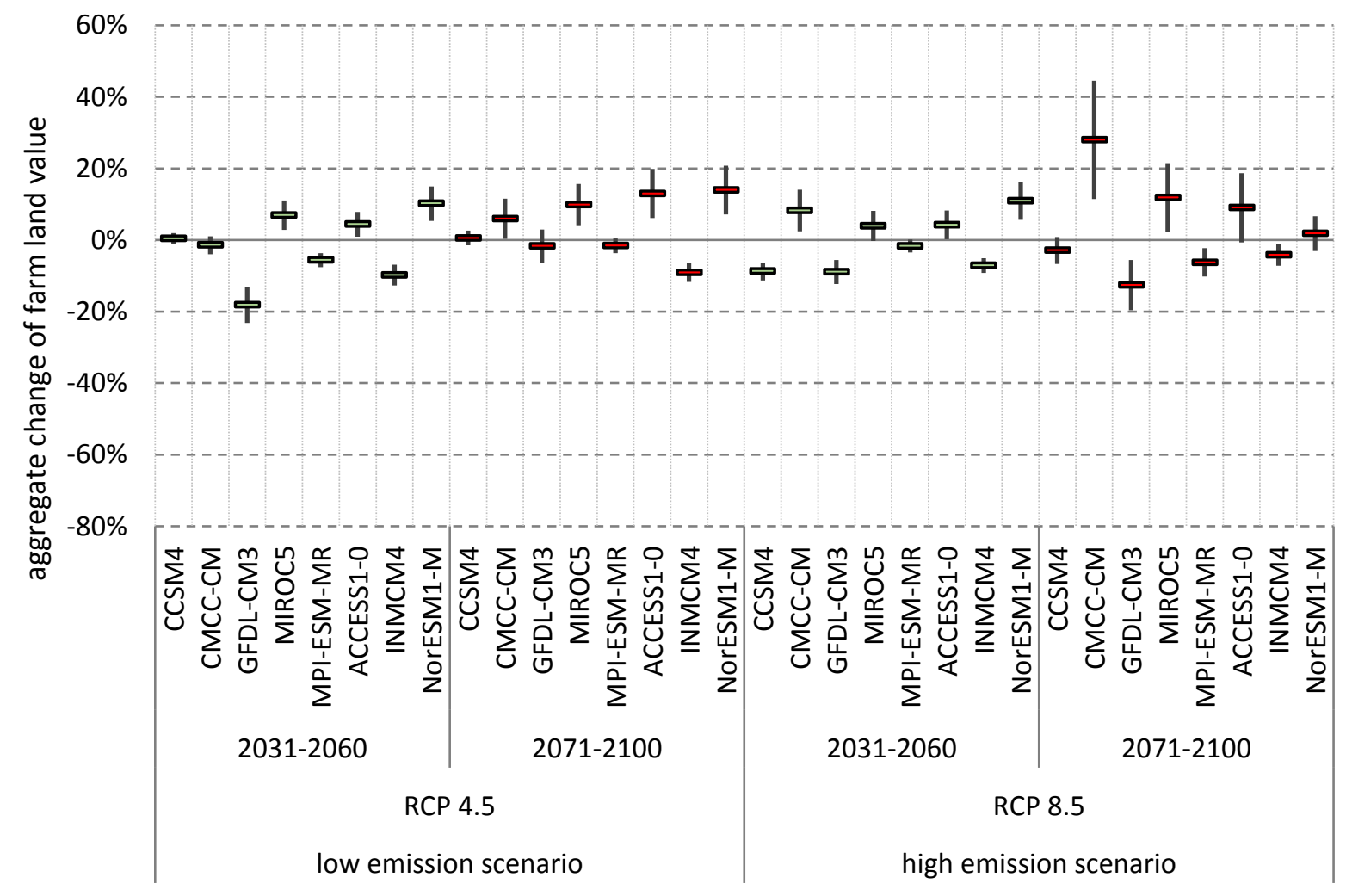

Fig. A12. Climate change impact on farmland values in Tuscany 


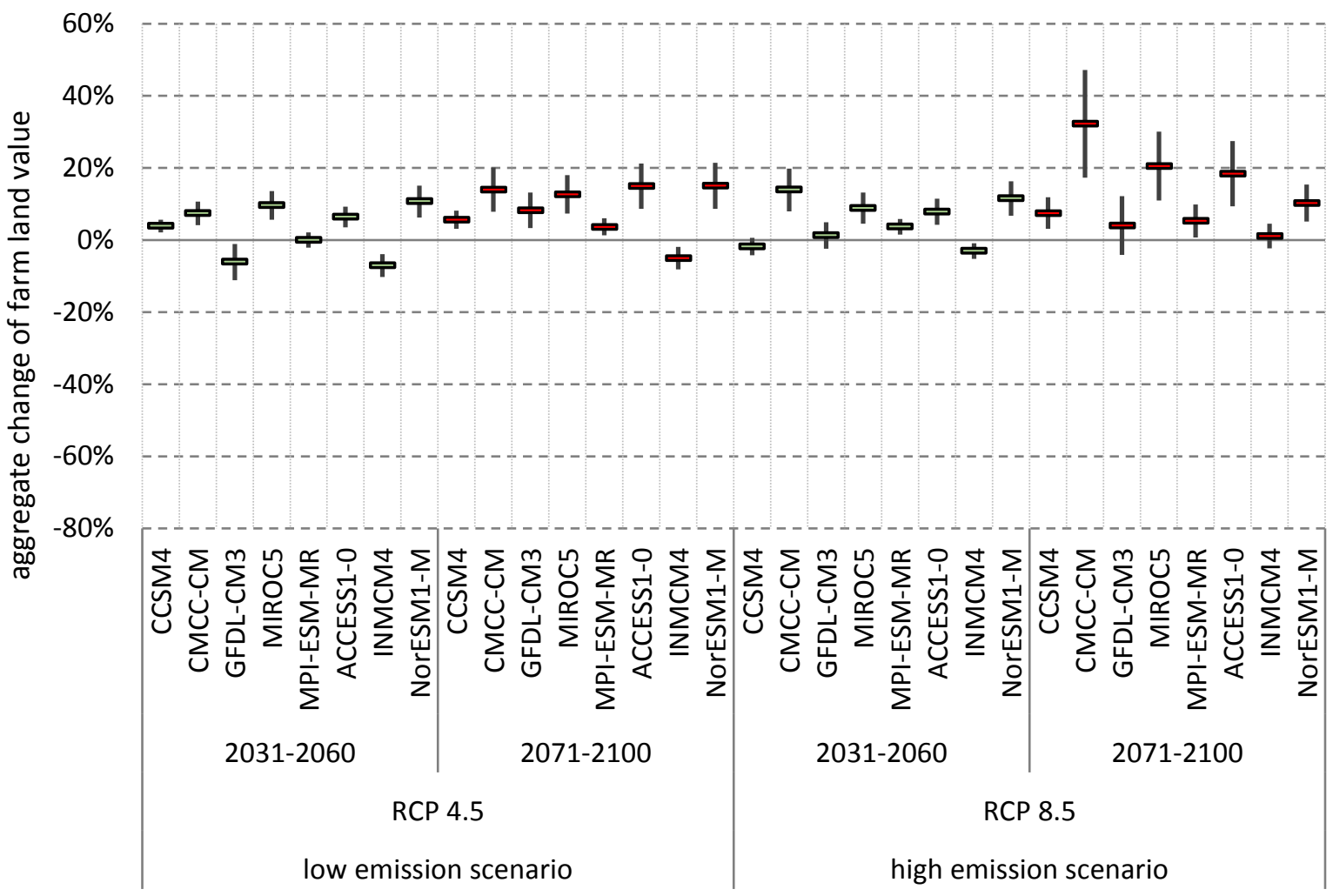

Fig. A13. Climate change impact on farmland values in Umbria

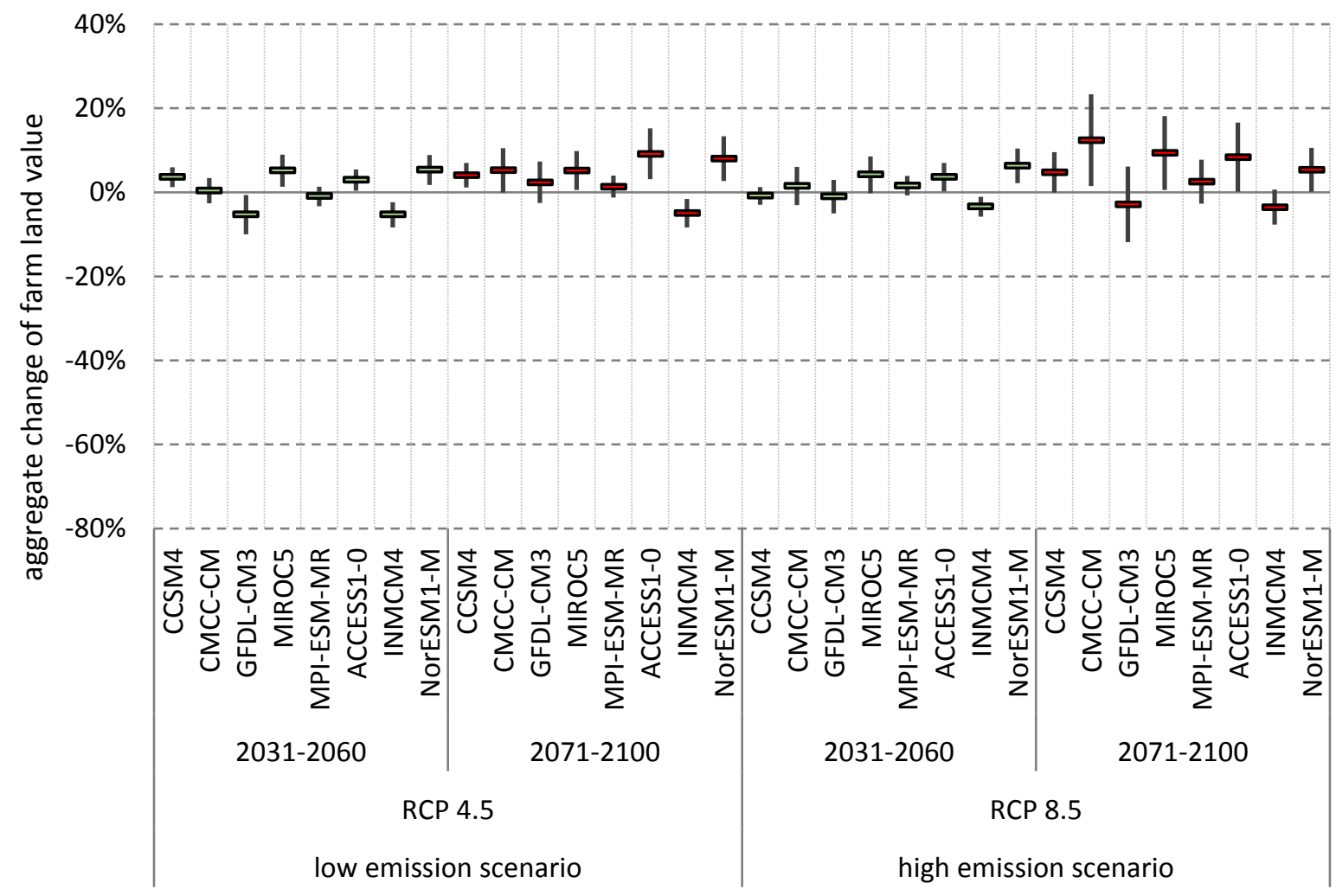

Fig. A14. Climate change impact on farmland values in Abruzzo 


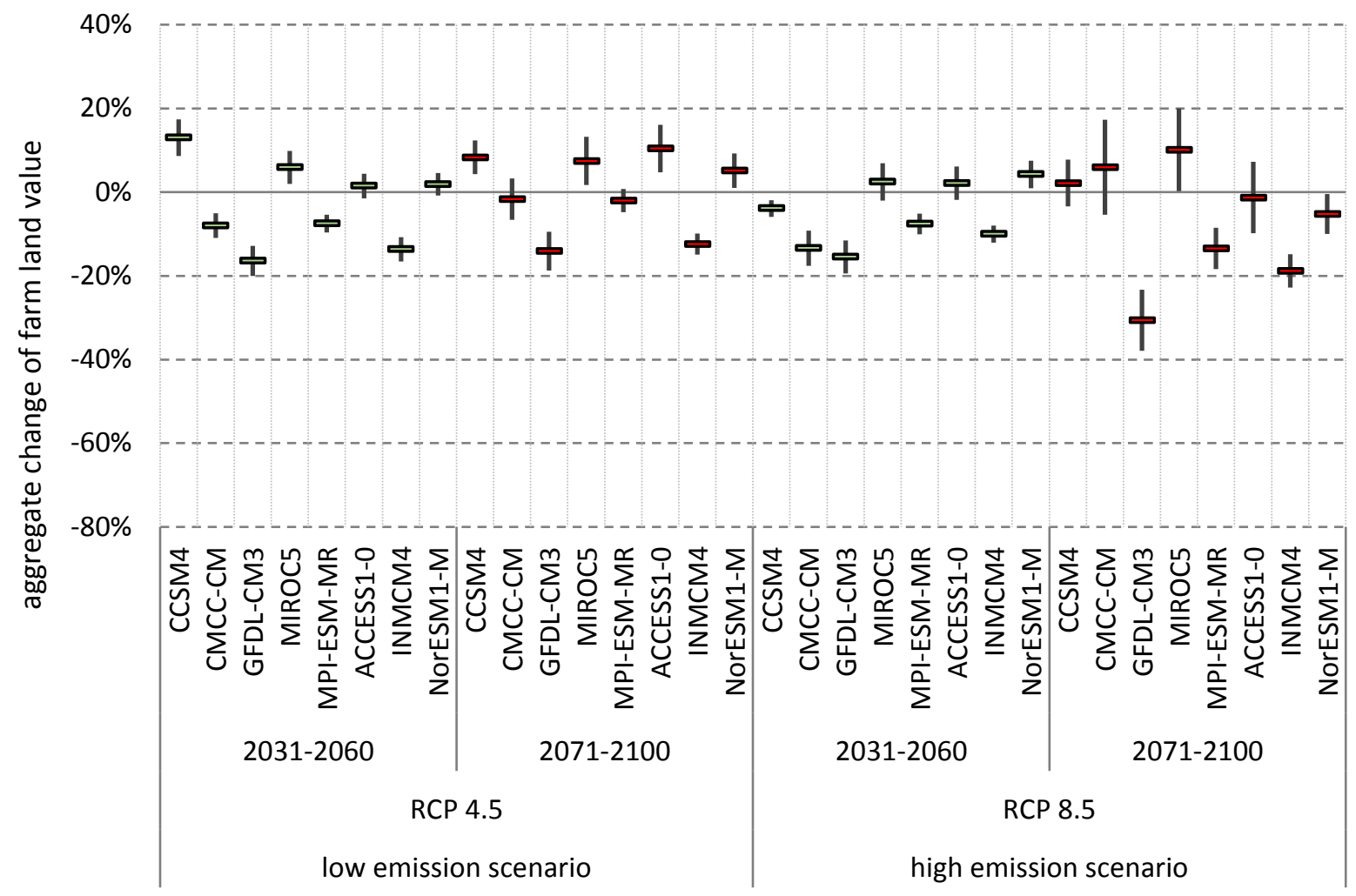

Fig. A15. Climate change impact on farmland values in Basilicata

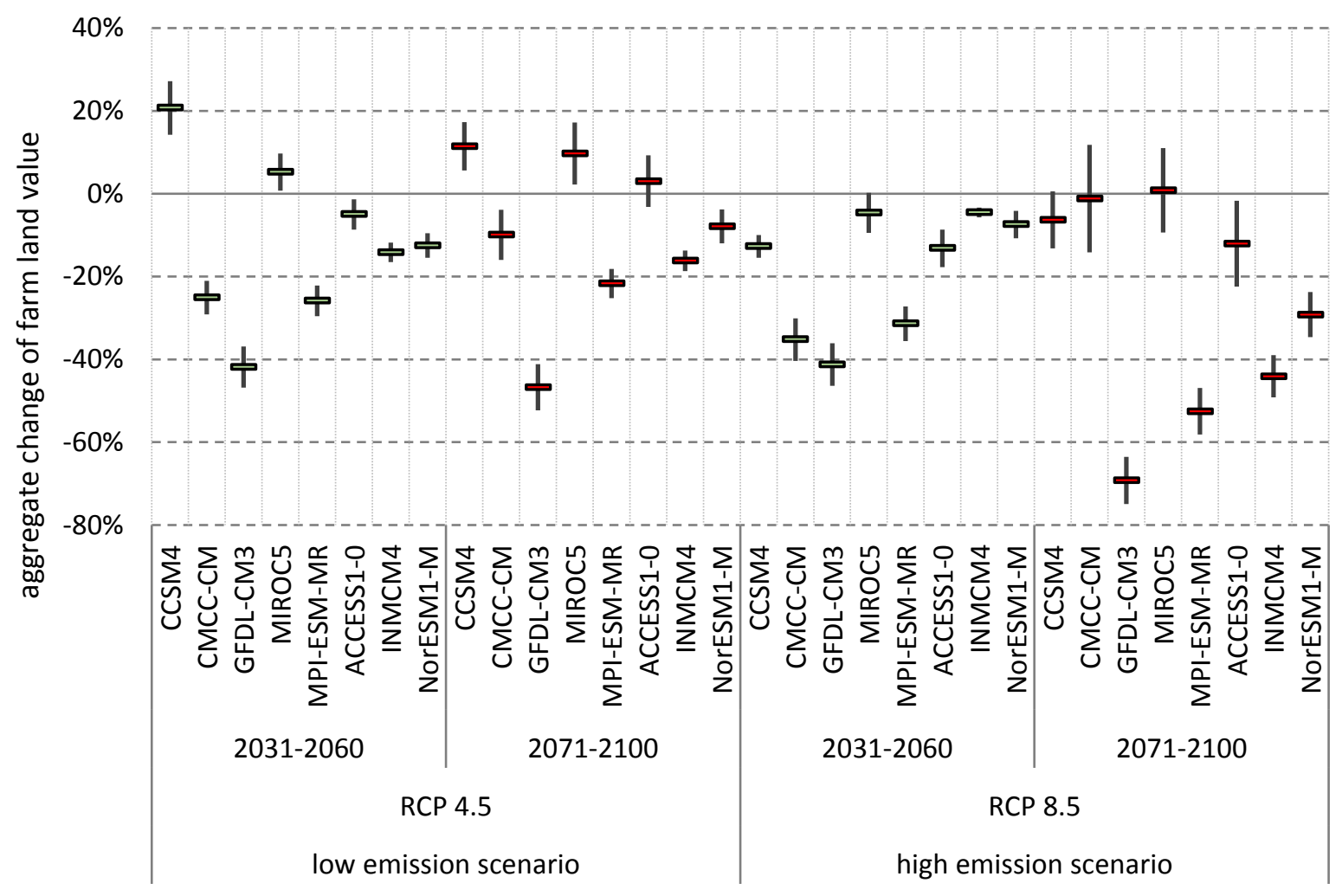

Fig. A16. Climate change impact on farmland values in Calabria 


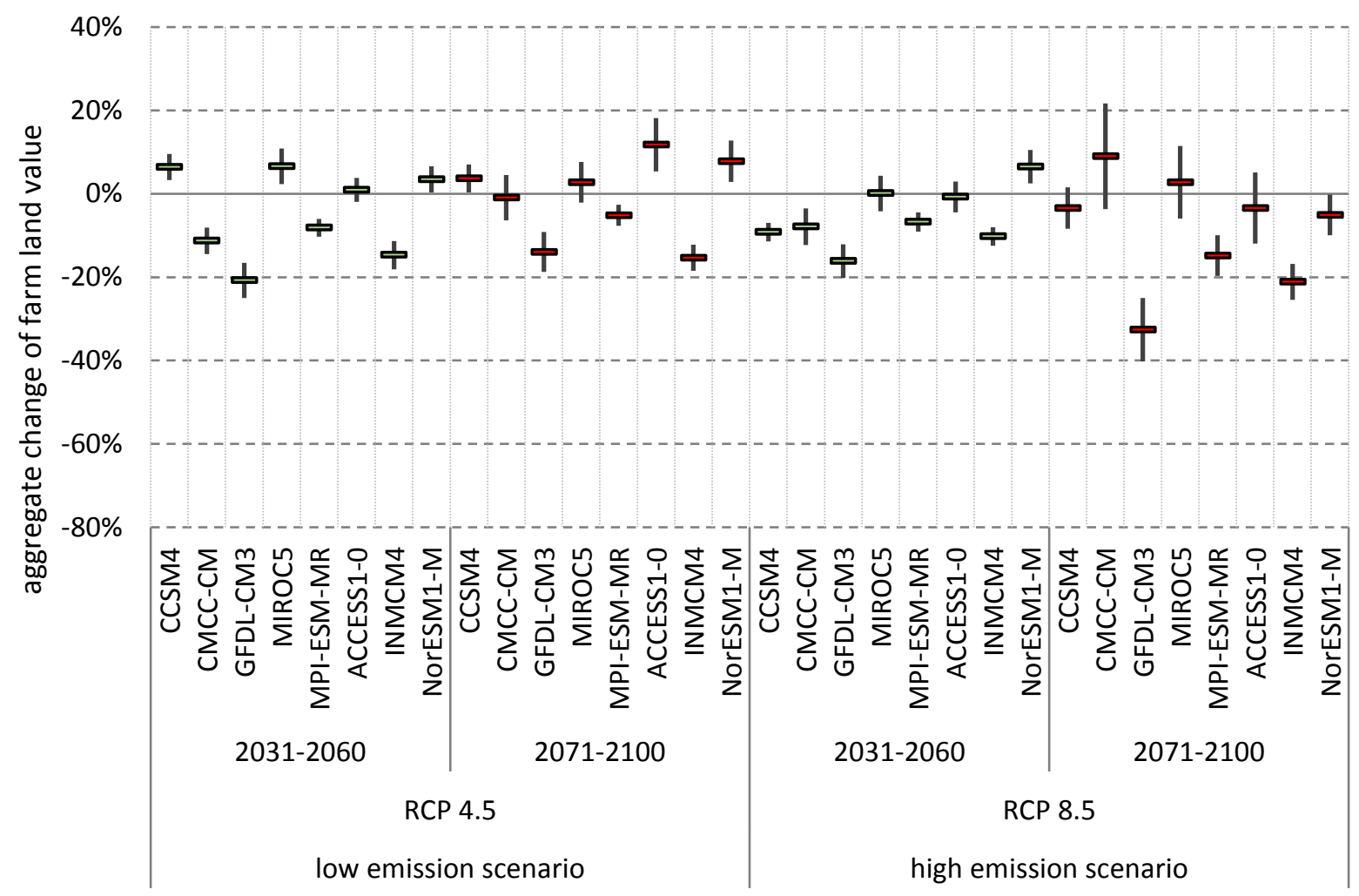

Fig. A17. Climate change impact on farmland values in Campania

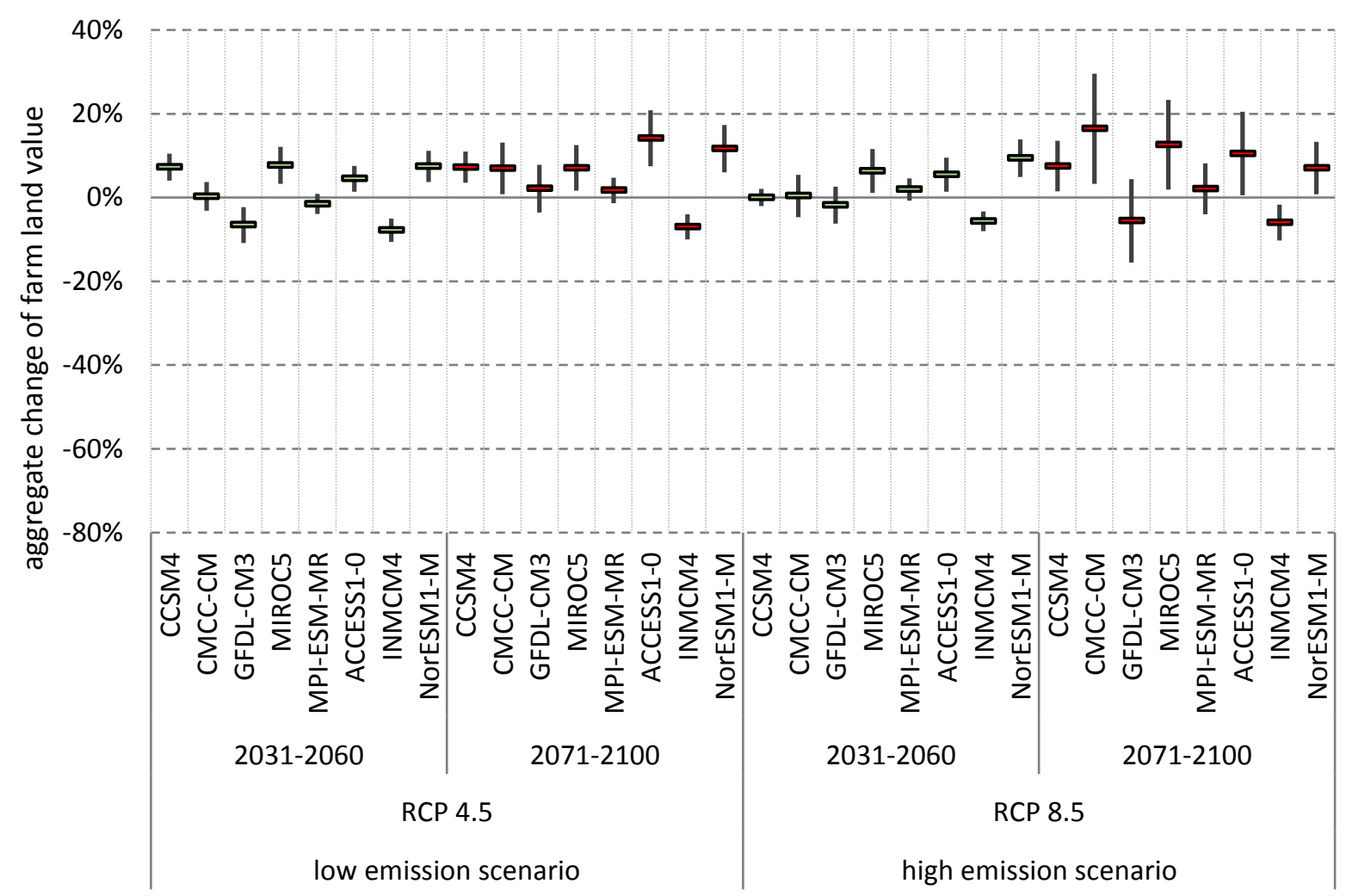

Fig. A18. Climate change impact on farmland values in Molise 


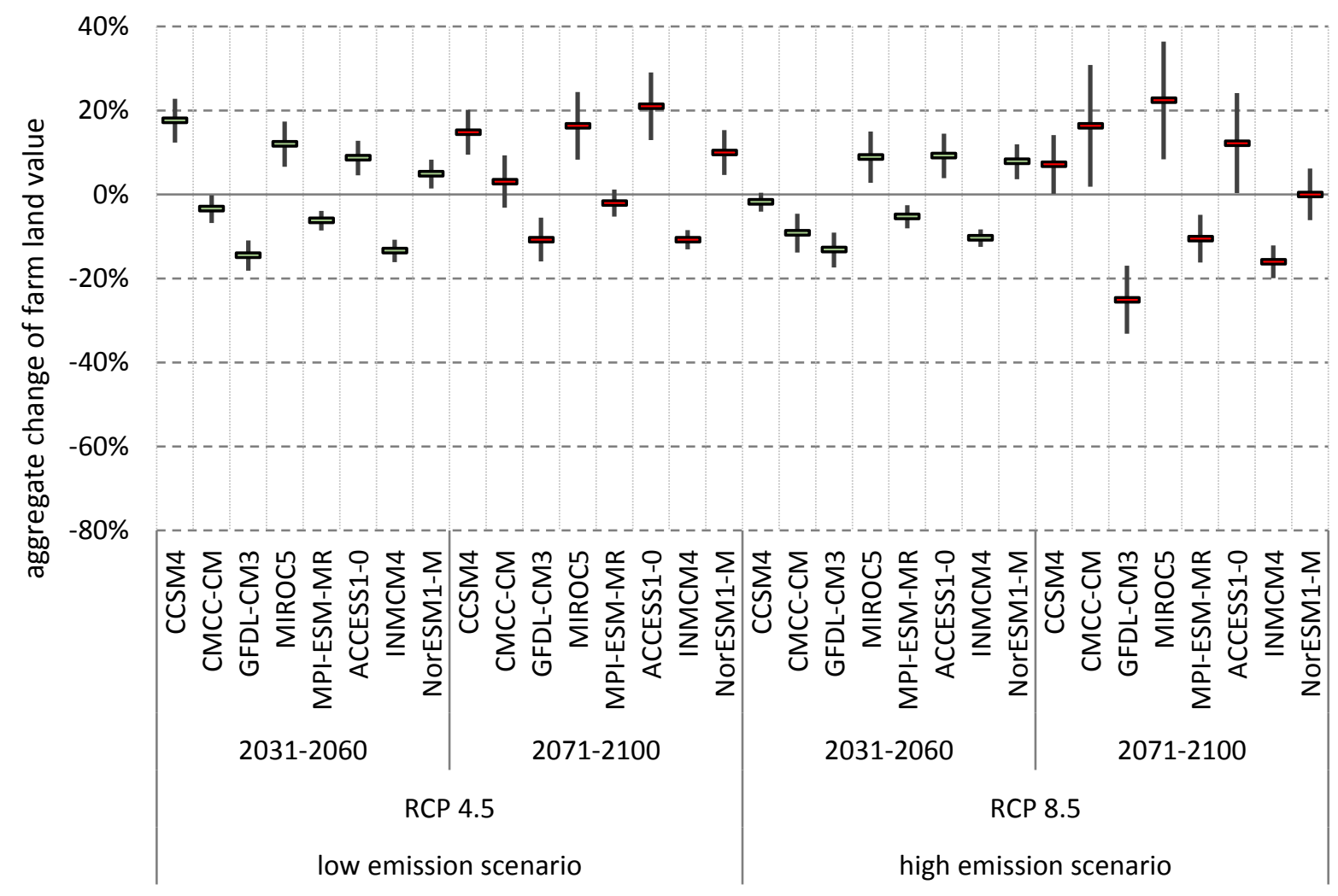

Fig. A19. Climate change impact on farmland values in Puglia

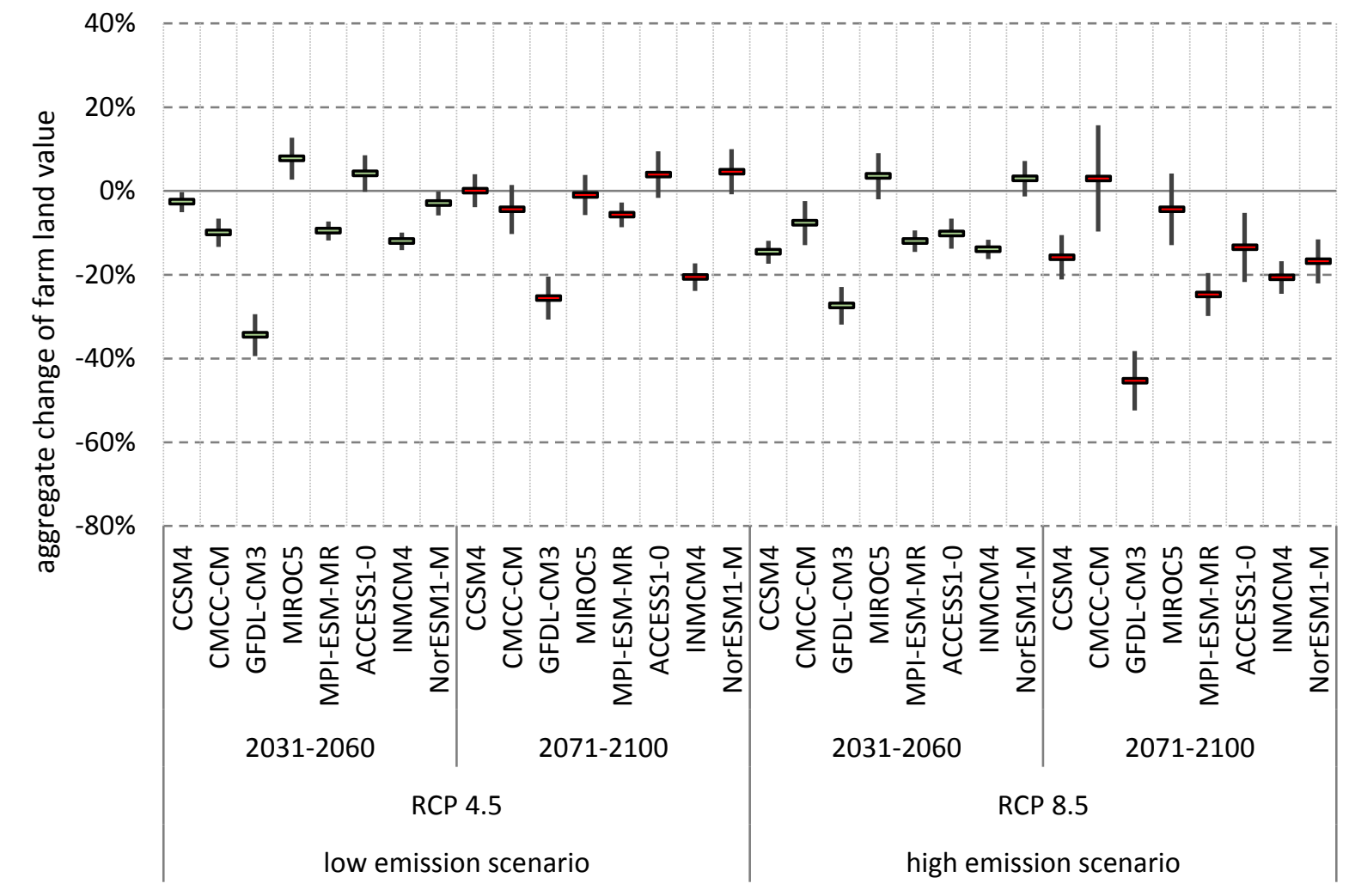

Fig. A20. Climate change impact on farmland values in Sardinia 


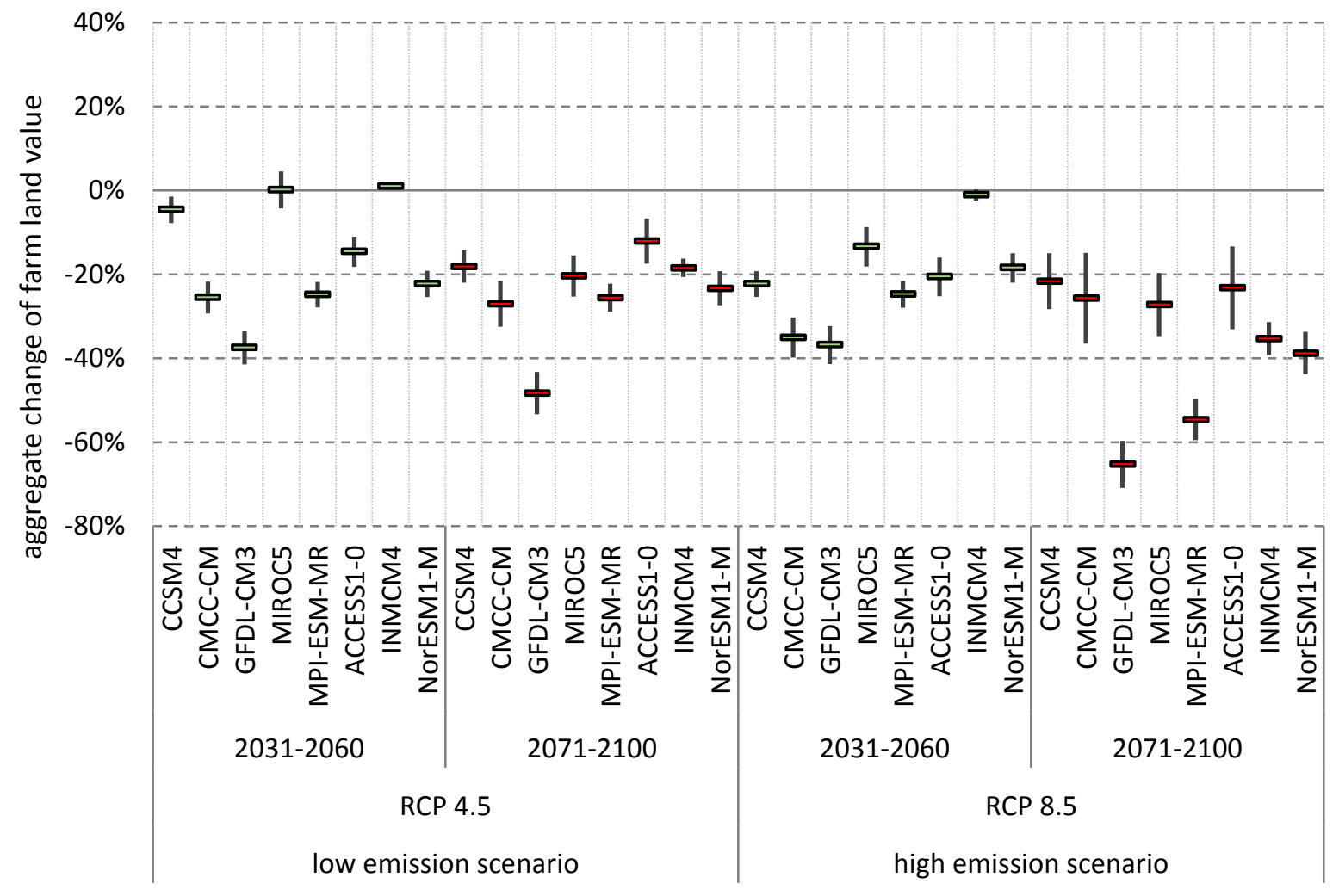

Fig. A21. Climate change impact on farmland values in Sicily 